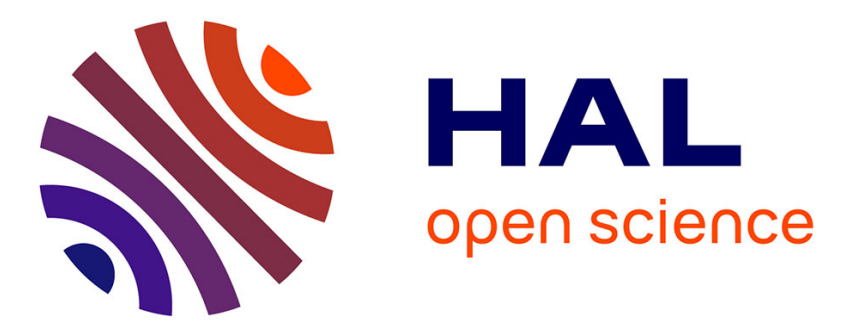

\title{
Crack initiation sensitivity of wrought direct aged alloy 718 in the very high cycle fatigue regime: the role of non-metallic inclusions
}

Damien Texier, Jonathan Cormier, Patrick Villechaise, Jean-Charles Stinville, Chris J. Torbet, Stéphane Pierret, Tresa M. Pollock

\section{To cite this version:}

Damien Texier, Jonathan Cormier, Patrick Villechaise, Jean-Charles Stinville, Chris J. Torbet, et al.. Crack initiation sensitivity of wrought direct aged alloy 718 in the very high cycle fatigue regime: the role of non-metallic inclusions. Materials Science and Engineering: A, 2016, 678, pp.122 - 136 . 10.1016/j.msea.2016.09.098 . hal-01662609

\section{HAL Id: hal-01662609 https://hal.science/hal-01662609}

Submitted on 13 Dec 2017

HAL is a multi-disciplinary open access archive for the deposit and dissemination of scientific research documents, whether they are published or not. The documents may come from teaching and research institutions in France or abroad, or from public or private research centers.
L'archive ouverte pluridisciplinaire HAL, est destinée au dépôt et à la diffusion de documents scientifiques de niveau recherche, publiés ou non, émanant des établissements d'enseignement et de recherche français ou étrangers, des laboratoires publics ou privés. 


\title{
Crack initiation sensitivity of wrought direct aged alloy 718 in the very high cycle fatigue regime: the role of non-metallic inclusions
}

\author{
Damien Texier ${ }^{\mathrm{a}, \mathrm{b}, \mathrm{c}, *}$, Jonathan Cormier ${ }^{\mathrm{a}}$, Patrick Villechaise ${ }^{\mathrm{a}}$, Jean-Charles Stinville ${ }^{\mathrm{b}}$, \\ Chris J. Torbet ${ }^{\mathrm{b}}$, Stéphane Pierret ${ }^{\mathrm{d}}$, Tresa M. Pollock ${ }^{\mathrm{b}}$ \\ a Institut Pprime - UPR CNRS 3346 - ISAE-ENSMA; Téléport 2, 1 avenue Clément Ader, BP 40109, Futuroscope-Chasseneuil Cedex 86961, France \\ b Materials Department, University of California Santa Barbara, Santa Barbara, CA 93106, United States \\ ${ }^{\mathrm{c}}$ Now at: Mechanical Engineering Department, Ecole de Technologie Supérieure, 1100 Rue Notre-Dame Ouest, Montréal, QC H3C 1K3, Canada \\ ' Safran aircraft engines; Site de Villaroche, Rond-Point René Ravaud, Moissy-Cramayel 77550, France
}

\section{A R T I C L E I N F O}

\section{Keywords:}

Very high cycle fatigue

Superalloy

Inconel 718

Carbide

Nitride

EBSD

\begin{abstract}
A B S T R A C T
Fatigue crack initiation in the direct aged version of the nickel-based superalloy Inconel 718 has been investigated at room temperature in the low stress/very high cycle regime via ultrasonic fatigue testing. Three different microstructures have been examined at the same strain amplitude in order to understand the influence of non-metallic inclusions (NMIs), i.e. carbides, carbonitrides and nitrides, and $\Sigma 3$ twin boundary density on lifetime and failure mode. A slight refinement in grain structure and a higher $\Sigma 3$ twin boundary density is associated with substantial reductions in lifetime. Decreasing $\Sigma 3$ twin boundary density for fine grain microstructures results in a change in crack initiation mechanism from strain localization within grains at the high end of the grain size distribution to cracking of NMIs. To study the early stages of crack initiation and growth, specimens with pre-cracked NMIs were also tested in order to examine the role of the surrounding grain structure. Pre-cracked NMIs mainly result in macroscopic failure initiation at NMIs independent of the wrought microstructure. However, pre-loading specimens within the plastic domain highlighted the competition in crack initiation mode between cracked-NMIs and favorably oriented twin boundaries. Crack arrest from most of the pre-cracked NMIs demonstrates that surrounding grain structure (grain orientation, local plasticity and roughness in the vicinity of crack tip due to pre-straining) play a key role in the fatigue life of components stressed in the nominal elastic regime.
\end{abstract}

\section{Introduction}

The direct aged version of the polycrystalline nickel-based superalloy Inconel 718 (DA718) is widely used to manufacture structural components requiring extremely high mechanical performance at intermediate and high temperatures. The $\delta$-subsolvus final forging step followed by aging heat treatment with no intermediate solution treatment enables a significant improvement of the yield strength and the low cycle fatigue (LCF) properties of this wrought alloy [1,2]. However, variability in microstructure and metallurgical state within an individual wrought component, i.e. grain size and $\delta$ and $\gamma$ "-phase content, are more pronounced in the direct aged version than in the standard annealed version of the alloy. Such material variability has recently been shown to strongly impact the low cycle fatigue life in the low-strain amplitude regime [3]. Non-metallic inclusions (NMIs), i.e. carbides, nitrides or carbonitrides, at the high end of the size distribution combined with low $\delta$-phase content $\left(f_{\delta \text {-phase }}<3.2 \%\right)-$ and inversely high $\gamma$ " precipitation content - can lead to a ten- to hundredfold reduction in fatigue life under these particular conditions [3]. Furthermore, fine grain microstructures (ASTM > 10) were demonstrated to be particularly sensitive to crack initiation when brittle surface or near-surface NMIs were present, especially at low temperatures [1,4-11]. While NMIs in fine grain IN718 alloys are important in this cycling regime, other microstructural features such as coarse favorably oriented grains or twin boundaries can also play a key role in the crack initiation process [12-15]. At lower cyclic stress amplitudes, i.e. for stress levels preventing the development of persistent slip bands (PSB), internal defects such as NMIs, favorably oriented large grains or twin boundaries generally lead to failure of structural materials [15-20]. Near-surface crack initiation is mainly attributed to the greater probability of finding a defect inside the material, compared to the surface. In the high cycle fatigue (HCF) and very high cycle fatigue (VHCF) regime, the influence of NMIs in Alloy 718 remains incompletely understood [20-25]. Cracks have been shown to

* Corresponding author at: Institut Pprime - UPR CNRS 3346 - ISAE-ENSMA; Téléport 2, 1 avenue Clément Ader, BP 40109, Futuroscope-Chasseneuil Cedex 86961, France. 
initiate within grains surrounded by Nb-rich carbides [23], "casting defects" [24] as well as favorably oriented grains [20-22,25]. Therefore, trade-offs in terms of microstructural features are required to ensure reliable design of structural components subjected to cyclic deformation, i.e. sufficiently high yield strength with a low sensitivity to strain localization. VHCF testing is an efficient means to survey critical microstructural features in materials in the low-strain/stress alternating loading regime. The aim of the present study is to examine the influence of surface and near-surface NMIs as well as coherent twin boundaries on the VHCF fatigue life of DA718 alloys. Microstructural variability has been examined via slight changes in forging parameters of DA718 pancakes in order to highlight the competition between crack initiation mechanisms involving NMIs compared to $\Sigma 3$ twin boundaries. In addition, the effect of the prior damage on VHCF lifetime was examined by means of introducing "natural cracks" within NMIs prior to VHCF testing.

\section{Experimental materials and procedures}

\subsection{Materials}

Three different microstructures of DA718 were investigated in the present study. These microstructures were obtained with dedicated thermomechanical treatments that varied the grain size, the twin boundary density and the $\delta$-phase content. All the microstructures were chosen to have a rather low $\delta$-phase content since this micro-structural parameter was recently noted to have a detrimental effect on the LCF fatigue life [3]. Six experimental pancakes were forged by Safran aircraft engines, with two pancakes per microstructure. The pancakes are denoted PAN-X, with $\mathrm{X}$ the number of the corresponding pancake. Forging parameters were chosen so that PAN-1 \& 2 and PAN-3 \& 4 pancakes have a microstructure comparable with the bore region microstructure in [3], i.e. the microstructure exhibiting high variability in fatigue life under LCF conditions at intermediate temperature.

PAN-5 \& 6 pancakes were specifically processed to slightly increase the grain size microstructure and decrease the twin boundary density in com-parison with the four previous pancakes. To avoid variations in chemical composition and non-metallic inclusion size distribution from one pancake to another one, the six different ingots were cut from the same billet. The nominal composition (in weight \%) of the billet was $\mathrm{Ni}-0.56 \mathrm{Al}-17.31 \mathrm{Fe}-0.14 \mathrm{Co}-17.97 \mathrm{Cr}-5.4 \mathrm{Nb}-\mathrm{Ta}-1.00 \mathrm{Ti}-0.023 \mathrm{C}-0.0062 \mathrm{~N}$.

\subsection{Microstructural characterization methods}

A FEI/Philips XL30 scanning electron microscope was used in secondary and back-scattered electron imaging modes in the $15-20 \mathrm{kV}$ range for conventional observations. The $\delta$-phase microstructure was revealed after the electrochemical polishing, consuming preferentially the $\gamma$ matrix in comparison to the NMIs and $\delta$-phase. Ten micrographs per microstructure were analyzed to statistically sample the variability of $\delta$-phase content for each microstructure. The resolution of the micrographs was adapted so that the smallest dimension of the $\delta$-phase was defined by at least five pixels. The $\delta$-phase fraction and morphology were images processed using $\mathrm{Fiji}^{\circledast}{ }^{\circledR}$ software with a similar algorithm as the one developed at Institut Pprime [26].

A conventional $\mathrm{JEOL}^{\mathrm{TM}} 6100$ scanning electron microscope equipped with OIM $^{\mathrm{TM}}$ software from EDAX was used for large electron backscattered diffraction (EBSD) scans. Large EBSD scans were carried out in order to characterize the grain size distribution and degree of texturing in the different microstructures. Areas measuring $280 \times 350$ $\mu \mathrm{m}^{2}$ were mapped according to a regular hexagonal grid pattern with a step size of $0.25 \mu \mathrm{m}$. Texture analyses were carried out from these large areas sampling more than 10,000 grains for PAN-1 to PAN-4 and 2,520 grains for PAN-5 \& 6. The calculation method used for the multiple of uniform density (MUD) was a harmonic series
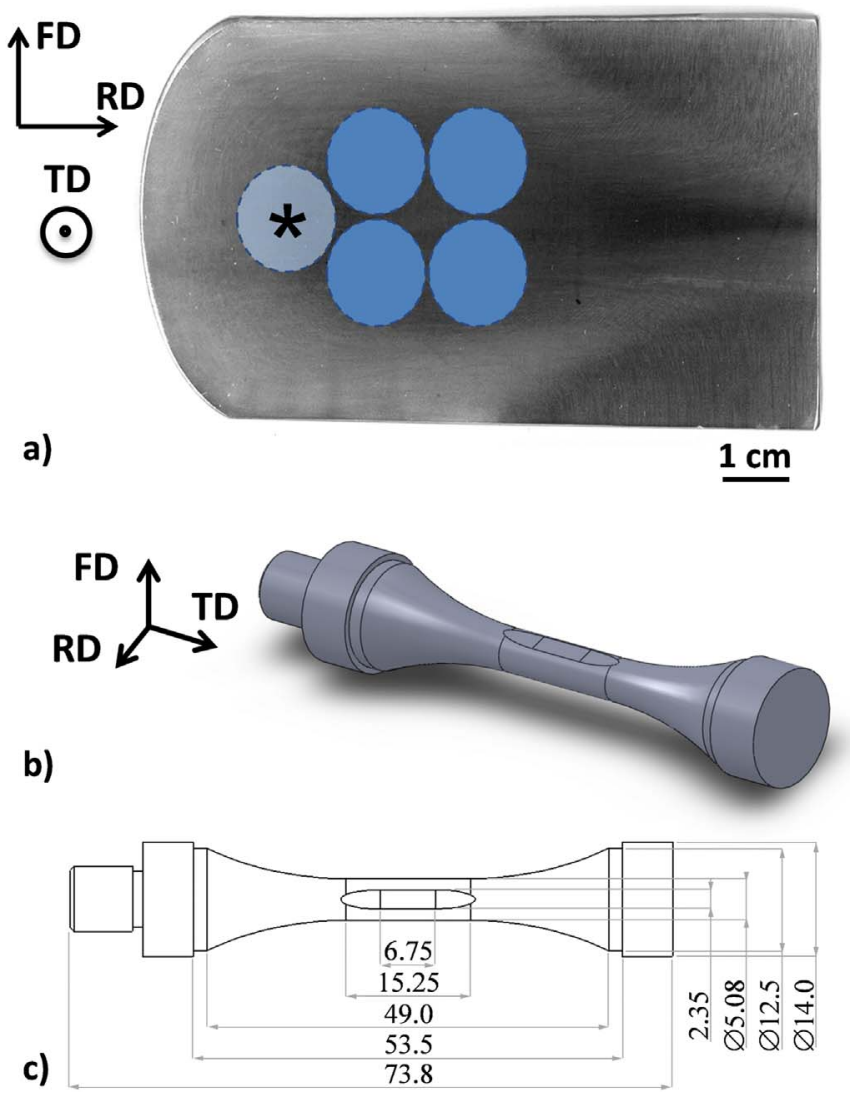

Fig. 1. a) Typical macrostructure of the pancake (FD-RD view) and schematic location of the extraction of the VHCF specimens, b) and c) Geometry of the VHCF specimens (all dimensions in millimeters).

expansion with a series rank of 21 and a Gaussian half-width of $0.25^{\circ}$. All the measurement points were used for the texture analyses to take into account the grain size effect on the MUD. The MUD was plotted on IPF maps with reference to the loading direction, since only uniaxial mechanical tests were performed in this study.

A FEI/Philips XL30 scanning electron microscope equipped with an OIM $^{\mathrm{TM}}$ software from EDAX acquisition setup was also used for local EBSD scans performed around cracks and NMIs favoring crack initiation. Local scans were performed on $120 \times 60 \mu \mathrm{m}^{2}$ areas with a $0.15 \mu \mathrm{m}$ step hexagonal pattern.

\subsection{Specimens preparation}

Prior to the extraction of the VHCF specimens, one slice was cut from each pancake to reveal the material grain flow within the pancakes produced by forging (Fig. 1a). The different directions, i.e. the forging direction (FD), the radial direction (RD) and the tangential direction (TD) are reported on the macrograph. Each slice was polished up to $1 \mu \mathrm{m}$ diamond and etched with a Kalling's II solution at $278 \mathrm{~K}$. VHCF specimens were machined out from homogeneous microstructural regions within PAN-2, PAN-4 and PAN-6 along the tangential direction (depicted as blue circle in Fig. 1a). The geometry of the VHCF specimens is given in Fig. $1 \mathrm{~b}$ and c. VHCF specimens were designed so that the first extensional resonance mode of the gage zone is at $20.0 \pm$ $0.5 \mathrm{kHz}$, the working frequency of the transducer used in the ultrasonic fatigue testing system. Particular care was taken during the lathe and EDM machining to limit the superficial residual stresses induced by machining. Two parallel flat areas were machined by electrodischarge machining (EDM) along the gage zone for high-resolution experimental observations (EBSD analyses and microindentation). Grooves were machined at specimen heads in order to grip the specimen under 
loading for interrupted tensile tests and microindentation under uniaxial loading. Each specimen gage and radius were then prepared with a 4000 grade $\mathrm{SiC}$ grit paper with an automatic device to gently remove at least $150 \mu \mathrm{m}$ in the radius. Following this, specimens were manually polished up to $1 \mu \mathrm{m}$ finish with diamond paste. Finally, each specimen was electrochemically polished under $15 \mathrm{~V}$ in a $10 \%$ vol. perchloric acid/90\% vol. ethylene glycol solution at $283 \mathrm{~K}$ to limit superficial residual stresses due to the mechanical polishing..

\subsection{Very high cycle fatigue testing (VHCF)}

VHCF testing was conducted under displacement control within the nominally elastic deformation regime under fully reversed loading ( $\varepsilon_{\max }=0.22 \%$ and $R_{\varepsilon}=-1$ ) using a $20 \mathrm{kHz}$ sinusoidal shape cycle at room temperature. During VHCF testing, the temperature was controlled both by an air-cooling system and by a very conservative "pulse time/pause time" ratio $(250 \mathrm{~ms} / 4000 \mathrm{~ms})$ to avoid self-heating of the sample during cycling. All the VHCF tests were conducted up to failure, but several tests were regularly interrupted to capture the first stages of crack initiation/propagation. Before each VHCF test, a calibration procedure was required to adapt the power supplied by the piezoelectric transducer to reach the targeted strain level at the gage zone. A strain gage mounted in the middle of the gage zone enabled to measure the dynamic strain loading. The dynamic strain was measured at different input power settings to correlate the power input of the transducer with the strain level in the gage zone of the VHCF specimen. The strain level applied during the calibration procedure was at least two times lower than the targeted strain level for the VHCF testing. According to the linear relationship between the maximal strain of the gage zone and the power supplied by the transducer, the power supplied by the transducer was hence extrapolated to reach the targeted strain level. Additional details on the experimental procedure are given by Shyam et al. [27]. A sample was denoted as a run-out when, at a given number of cycles $\left(2.5 \times 10^{8}\right.$ cycles $)$, no cracks were observed at the surface.

\subsection{Damage introduction prior to VHCF experiments}

To investigate the first stages of crack propagation from NMIs, two procedures were adopted to crack selected NMIs prior to VHCF testing. Interrupted tensile tests within the plastic domain and microindentations under uniaxial loading within the elastic regime enabled precracking of the different kinds of NMIs, i.e. the carbides, the nitrides and the carbonitrides. For damage introduction by interrupted tensile testing, VHCF specimens were loaded up to $1250 \mathrm{MPa}$ on an Instron model 5582 screw-driven machine. This stress level was chosen to crack around $10 \%$ of NMIs and to limit overall plastic strain [3]. Specimens were gripped at grooves. The strain was continuously measured with a strain gage mounted on the gage zone and the load was continuously recorded to assess the monotonic tensile properties of the different microstructures along the TD direction. In the case of damage introduced by microindentations under loading, VHCF speci-mens were loaded within the macroscopic elastic deformation regime (to 800 MPa). Specimens were screwed on the threaded end side and gripped at groove one the other side for lens accessibility. A Vickers indenter tip was used to locally add an increment of load $(200 \mathrm{mN})$ until the NMIs cracked. Between twenty to thirty coarse NMIs were fractured per VHCF specimen. Fiducial markers were used to insure perpendicularity between the flat area of the gage zone and the loading direction of the microhardness device. Only one of the two flats of the VHCF specimens was microindented for further observations.

\subsection{Interrupted $\mathrm{VHCF}$ tests}

Some interrupted VHCF tests were also conducted to follow the crack propagation from several initiation sites, i.e. the pre-cracked
NMIs. After damage introduction, the two flats of the VHCF specimens were mapped to observe all the NMIs in the SEM for the VHCF specimens damaged by interrupted tensile tests. In the case of VHCF specimens damaged by microindentation, only the microindented flat was studied. The XY positions were reported and a micrograph was taken for all the pre-cracked NMIs. Twenty to thirty NMIs per flat section were observed at different fractions of the total VHCF life.

\subsection{In-situ tensile testing}

In-situ SEM tensile testing was performed using a JEOL ${ }^{\mathrm{TM}} 6100$ SEM equipped with a DEBEN micro-machine. Tests were conducted in displacement control with a strain rate of the order of $10^{-4} \mathrm{~s}^{-1}$. The loading was interrupted at various stress levels for local observation of microstructure and slip offsets. Interruptions were made at $500 \mathrm{MPa}$, $1000 \mathrm{MPa}$, then every $25 \mathrm{MPa}$ up to $1400 \mathrm{MPa}$ and every $15 \mathrm{MPa}$ over $1400 \mathrm{MPa}$. The purpose of this test was to investigate the density of cracked non-metallic inclusions (TiN and $\mathrm{NbC}$ ) as a function of the strain/stress level. A representative population of 150-200 inclusions was randomly chosen on the gage zone for observation.

\section{Results}

\subsection{Microstructure analyses}

\subsubsection{Grain structure and texture}

The grain structure of the six pancakes was characterized by EBSD. Large areas in a TD-RD plane view were scanned to sample a sufficient number of grains for accurate representation of grain size distribution. As depicted in Fig. 2, the microstructure of the different pancakes was represented with the inverse pole figure (IPF) maps according to the tangential direction of the pancake, i.e. the loading direction of the VHCF specimens. All material variants exhibited equiaxed grains containing annealing twins. A finer grain size was observed for PAN1 to PAN-4 in comparison with PAN-5 \& 6, as shown by the grain size distributions (Fig. 3). For quantitative grain size analyses, twins were removed by pseudo-symmetry corrections. A Gaussian function has been plotted on each grain size distribution according to parameters measured with EBSD (the mean grain size and the standard deviation) for qualitative analyses (black dashed curves in Fig. 3). PAN-1 \& 2 grain size distribution matched relatively well with a Gaussian distribution while PAN-3 \& 4 and PAN- 5 \& 6 grain size distributions departed from a Gaussian distribution due to the non-negligible occurrence of coarse grains at the tail of the grain size distribution (grain diameter $>20 \mu \mathrm{m}$ and $25 \mu \mathrm{m}$, respectively). In addition, PAN-3 \& 4 exhibits a relatively high fraction of fine grains (grain diameter $<10 \mu \mathrm{m}$ ), with a bimodal population of grain size distribution, as illustrated in Figs. $2 \mathrm{~b}$ and $3 \mathrm{~b}$. A summary of these results is reported in Table 1 . Since $\Sigma 3$ twin boundaries $(\Sigma 3 \mathrm{~TB})$ have been associated with crack initiation under cyclic loading $[15,18,28-30]$, their fraction and length per surface area were calculated and reported in Table 1 . While differences in grain size distribution are relatively minor between PAN-1 \& 2 and PAN-3 \& 4 microstructures, the $\Sigma 3 \mathrm{~TB}$ length per surface area was higher for the PAN-3 \& 4 microstructures with comparable $\Sigma 3$ TB length fraction. Due to a coarser microstructure, PAN-5\&6 exhibited a similar $\Sigma 3 \mathrm{~TB}$ fraction to PAN-1\& 2 but a clearly lower $\Sigma 3$ TB length per surface area...

As depicted in Fig. 4, the multiple of uniform density (MUD) maps were plotted for each of the pancakes to statistically describe the texture. MUD maps represented on IPF maps according to the loading direction did not exhibit strong preferential crystallographic orientations, with the highest texture index being 1.88, Fig. 4c. The texture index is reported in Table 1 for each of the different pancakes..

\subsection{2. $\delta$-phase microstructure}

The $\delta$-phase morphology was similar for the three versions of Alloy 

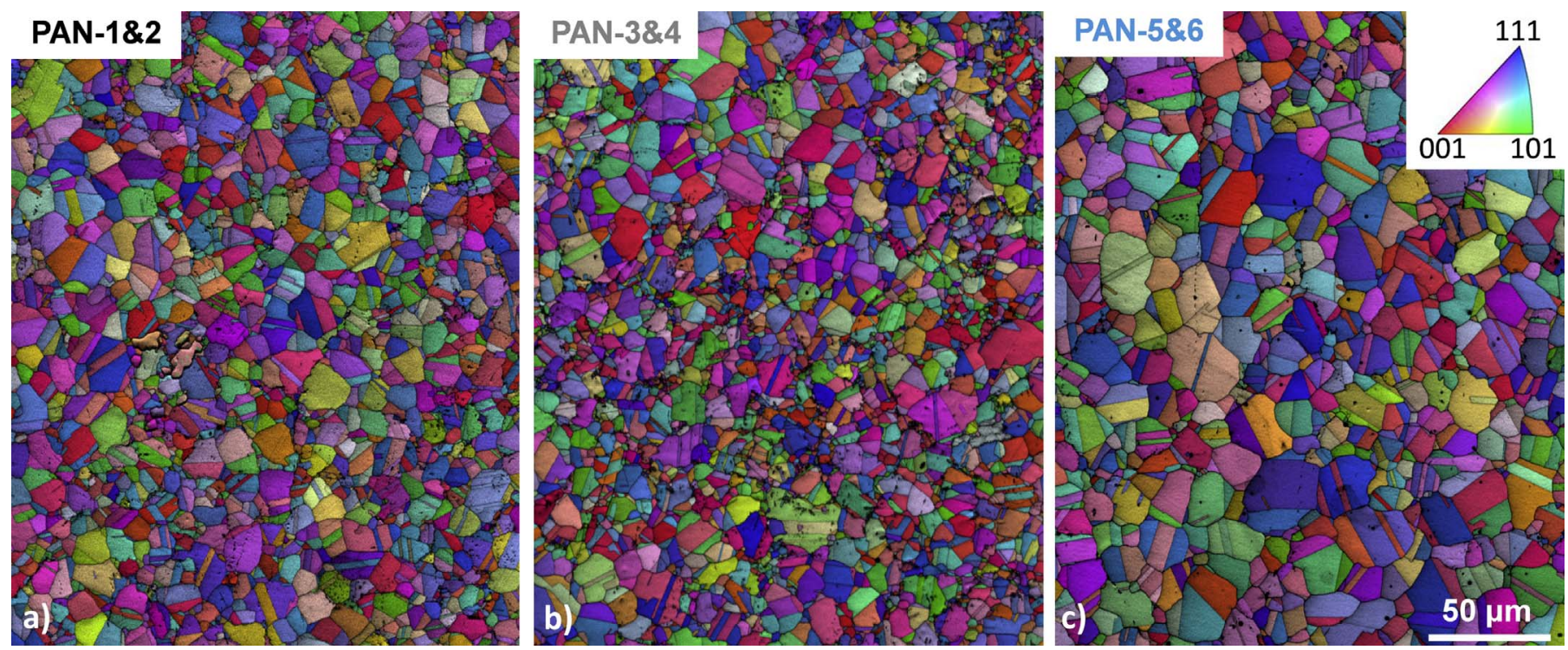

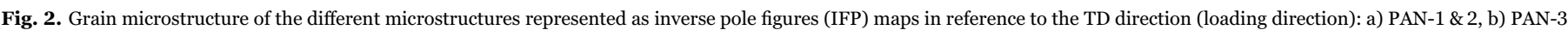
\& 4 , c) PAN-5 \& 6 .

718 investigated in the present study (Fig. 5). A combination of globular and platelet shaped $\delta$ precipitates decorate the original austenitic grains boundaries prior to recrystallization. Qualitative differences in $\delta$-phase fraction were clearly observed between the different microstructures. PAN-3 \& 4 exhibited a higher $\delta$-phase fraction than PAN-1\&2 and PAN-5\&6. A summary of these results is reported in Table 1.

\subsection{VHCF experiments on the "as-received" pancakes}

\subsubsection{VHCF Lifetime of the "as-received" specimens}

The VHCF properties of the pancakes were measured at room temperature under fully reversed cycling up to failure. The number of cycles to failure is reported in Fig. 6 as a function of the maximum strain level. Two populations of lifetimes were clearly noticeable. Tests conducted on PAN-2 and PAN-4 failed between 2 and 5 million cycles while run-outs were observed for PAN-6 ( $N_{f}>250$ million cycles). One PAN-6 VHCF specimen test was continued up to 1 billion cycles without any macroscopic failure and no occurrence of surface cracks. VHCF results are reported in Table 2.

\subsubsection{Fracture surface and gage zone analyses}

After VHCF lifetime experiments, fracture surfaces were observed in order to determine the initiation failure mode, when possible. All the specimens failed due to the growth of a single fatigue crack. All initiation sites were located at the surface or in near-surface (<
$50 \mu \mathrm{m})$ regions, independent of the microstructure. Only a direct comparison between PAN-2 and PAN-4 failure modes can be performed since PAN-6 experiments were all interrupted before failure. Observations in the backscattered mode enable a better identification of the chemical nature of the initiation site. The three PAN-2 VHCF specimens failed within near-surface clusters of nitrides (Fig. 7a, b and c). As far as the PAN-4 microstructure is concerned, crack initiation within a coarse grain (diameter $>20 \mu \mathrm{m}$ ) leads to macroscopic failure (Fig. $7 \mathrm{e}$ and $\mathrm{f}$ ) or at a cluster of carbides (Table 2). It is worth mentioning that crack initiation in PAN-4 occurred on a grain on the high end of the tail of the grain size distribution shown in Fig. 3b. Crack initiation within a coarse grain is associated with a slightly lower lifetime than in the case of crack initiating at NMIs. Fractographic analyses are reported in Table 2. Surface contact due to the fully reversed loading is denoted "S.C." in the table..

\subsubsection{Crack density on the gage zone at the specimen surface}

The gage zones of the different VHCF samples were observed in order to evaluate the crack density after a prescribed number of cycles. Some tests were regularly interrupted for gage zone observations under SEM. No cracks were observed at $80 \%$ of the life for any of the six materials and even at $95 \%$ of the life for PAN-1 \& 2 microstructure. In the present study, most of the VHCF specimens failed due to the growth of a single macroscopic crack. Furthermore, no cracking was observed far away from the macroscopic failure, independent of the microstructure of the specimen. Only few small cracks, i.e. few longer
PAN-1\&2

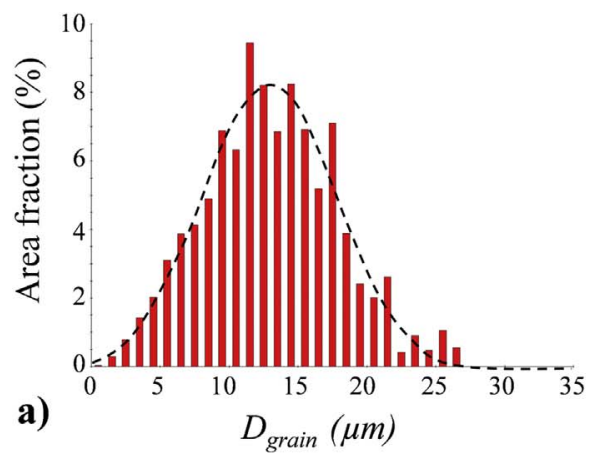

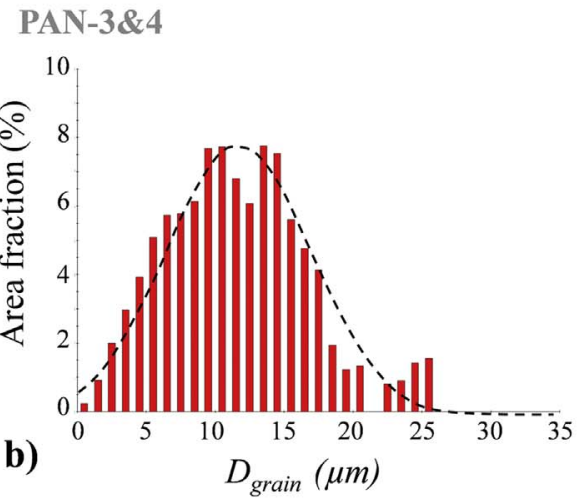

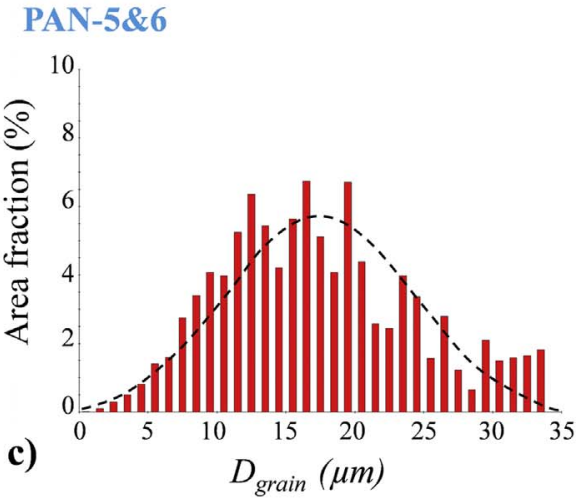

Fig. 3. Grain size distributions for the different microstructures: a) PAN-1 \& 2, b) PAN-3 \& 4, c) PAN-5 \& 6 . 
Table 1

Summary of different microstructural parameters for the different microstructures (grain size, grain boundary (GB), twin boundary (TB), texture index and $\delta$-phase fraction).

\begin{tabular}{|c|c|c|c|c|c|c|c|}
\hline \multirow[t]{2}{*}{ Reference } & \multicolumn{3}{|c|}{ Grain size $(\mu \mathrm{m})$} & \multicolumn{2}{|l|}{ 乏3 TB } & \multirow{2}{*}{$\begin{array}{l}\text { Max. texture } \\
\text { index }\end{array}$} & \multirow{2}{*}{$\begin{array}{l}\text { 8-phase fraction } \\
(\%)\end{array}$} \\
\hline & Mean value & $\begin{array}{l}\text { Max } \\
\text { value }\end{array}$ & $\begin{array}{l}\text { Standard } \\
\text { deviation }\end{array}$ & $\begin{array}{l}\text { TB length fraction } \\
(\mathrm{mm} / \mathrm{mm})\end{array}$ & $\begin{array}{l}\text { TB length/surface area } \\
\left(\mathrm{mm}^{-1}\right)\end{array}$ & & \\
\hline PAN-1 \& 2 & 13.0 & 26.5 & 4.9 & 0.41 & 207 & 1.70 & 1.5 \\
\hline PAN-3 \& 4 & 11.6 & 25.5 & 5.2 & 0.37 & 235 & 1.85 & 2.0 \\
\hline PAN-5 \& 6 & 17.4 & 33.5 & 7.0 & 0.42 & 154 & 1.88 & 0.8 \\
\hline
\end{tabular}

cracks spanning multiple grains, were observed close to the fatal crack (100-200 $\mu \mathrm{m}$ far from the crack), where stress intensity is known to be higher. This observation highlights the fact that a very high fraction of fatigue life is spent in crack initiation during VHCF testing of Alloy 718.

\subsubsection{Nature of the crack initiation sites for the different microstructures}

VCHF lifetimes for the different microstructures were plotted as a function of various microstructural features, i.e. the grain size, the twin boundary density and the $\delta$-phase content (Fig. 8). Specimens experiencing the longest fatigue lives have the coarsest grain size, the lowest twin boundary density and the lowest $\delta$-phase content (PAN-5 \& 6). Interestingly, PAN-1\&2 microstructure, having a lower $\Sigma 3$ twin boundary density failed due to crack initiation within nitrides and clusters of nitrides, while twin boundaries within large grains were identified as a weak feature for the PAN-3 \& 4 microstructure.

\subsection{VHCF experiments on pre-damaged specimens}

\subsubsection{Pre-damage introduction}

As mentioned in Section 2.4, damage prior to VHCF testing was introduced on some VCHF specimens in order to investigate the influence of pre-cracked NMIs on VHCF lifetime and on the early stages of crack propagation. The aim of such a procedure was to develop "natural" cracks within NMIs to better understand why very low LCF life is associated with crack initiation from the surface of NMIs [3]. Two different procedures for the introduction of damage were developed: interrupted tensile testing and microindentation under loading within the macroscopic elastic regime.

Interrupted tensile experiments were conducted on the different microstructures up to $1250 \mathrm{MPa}$. The stress - strain curves are plotted in Fig. 9 for the different pancakes. The onset of macroscopic plasticity was observed for all the microstructures between 1050 and $1150 \mathrm{MPa}$. Since the yield stress was different from one microstructure to another, residual plastic strains after pre-damaging in this manner were about
$0.13 \%, 0.09 \%$ and $0.18 \%$ for PAN-2, PAN-4 and PAN-6, respectively. This stress/strain level was also sufficient to crack several NMIs within each sample. Some examples of pre-cracked NMIs are illustrated in Fig. 10a, b and c. Slip bands within the metallic matrix were present in some grains surrounding the NMIs (shown by white arrows in Fig. 10a). Local plasticity within the grains connected with pre-cracked NMIs was also noticed in the vicinity of the crack tip (shown by white arrows in Fig. 10b). In that case, the crack within the NMI was relatively open. Conversely, Fig. 10c clearly exhibited a region with a relatively closed crack.

A second pre-cracking procedure which involved microindentation under uniaxial loading within the macroscopic elastic domain was also investigated. The tensile condition ( $800 \mathrm{MPa}$ ) was at least $80 \%$ of the macroscopic yield stress of each of the microstructures. The additional load applied by microindentation was enough to crack the majority of the NMIs. Some examples are given in Fig. 10d, e and f. Fig. 10d illustrates a carbide which is cracked across its diameter while in Fig. 10e a partially cracked carbide was introduced by the indentation. As depicted in Fig. 10f, some non-indented carbides were observed to be cracked, presumably due to the stresses induced during forging or pre-straining in the high macroscopic elastic regime.

Finally, the major difference between these two methods of introducing cracks within NMIs is the level of plasticity introduced within the bulk material and/or surrounding grains. Indeed, cracking NMIs with the microindentation technique imparts no bulk plasticity, hence allowing for a more direct comparison of the VHCF lifetime evolution with/without cracks in the NMIs.

\subsubsection{In-situ monotonic tensile testing}

In-situ tensile tests were conducted at room temperature on a specimen with a microstructure comparable to the PAN-1\&2 and PAN-3 \& 4 pancakes (bore region microstructure in ref. [3]) in order to investigate the stress level required to fracture individual NMIs under monotonic loading. Hundreds of NMIs, i.e. TiN and NbC inclusions, were observed at various stress levels in order to calculate the fraction

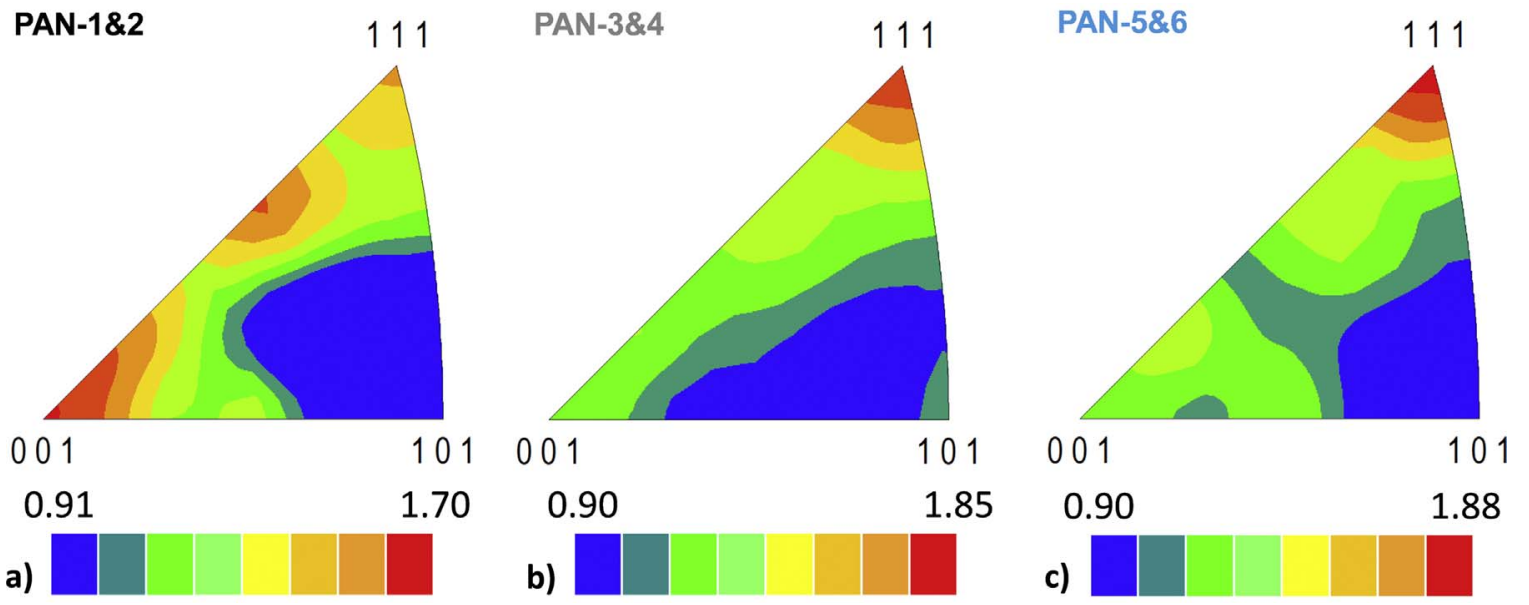

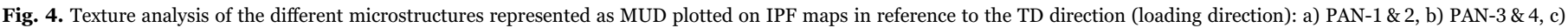
PAN-5 \& 6 . 

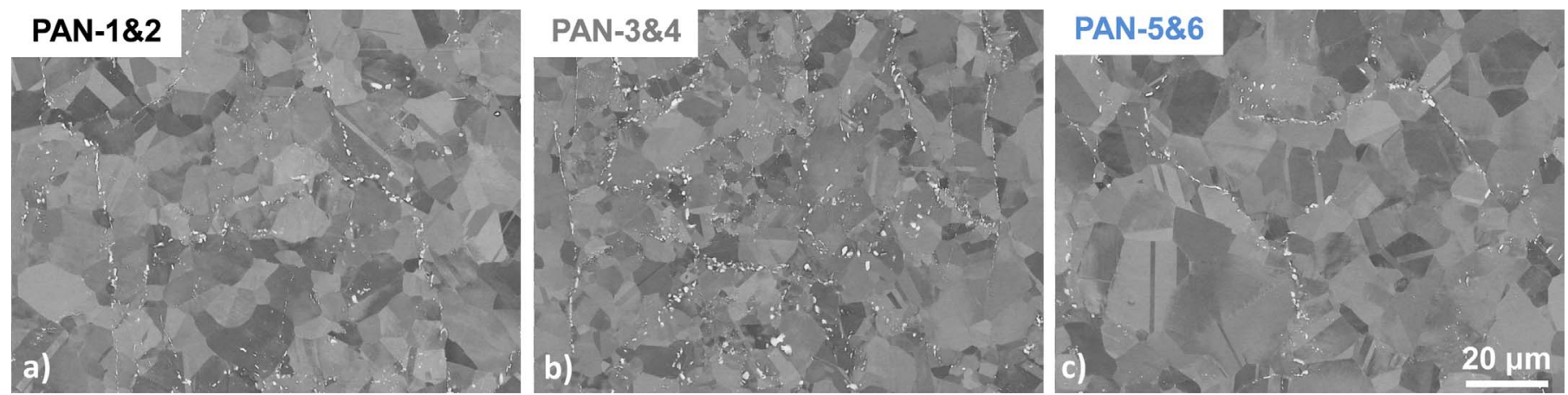

Fig. 5. $\delta$-phase microstructure representative of the different microstructures: a) PAN-1 \& 2, b) PAN-3 \& 4, c) PAN-5 \& 6 .

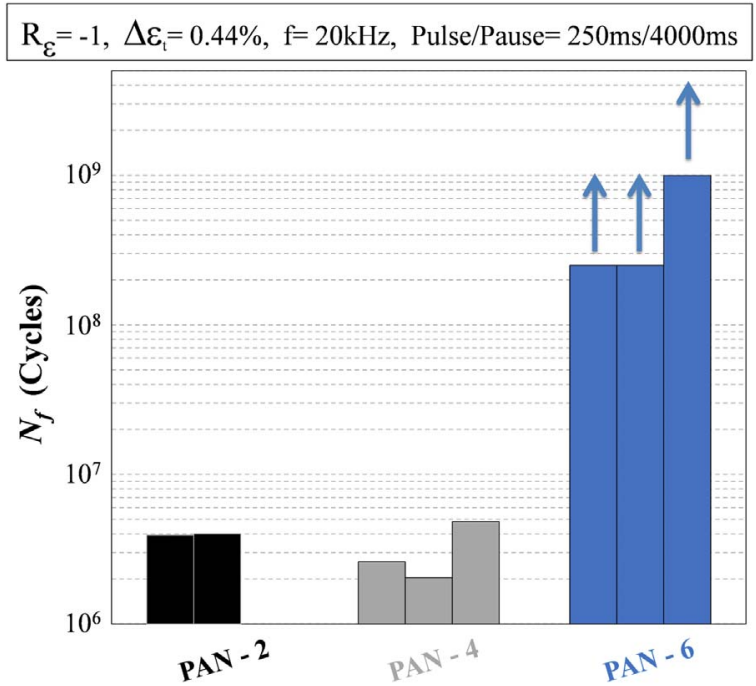

Fig. 6. VHCF lifetime for the different pancakes (as received VHCF specimens). Arrows correspond to run-out tests.

of fractured NMIs as a function of the stress level, as depicted in Fig. 11. The fraction of cracked NMIs shows a plateau in the macroscopic elastic domain then starts to progressively increase over yielding, as reported in ref. [3]. Interestingly, the fraction of fractured TiN inclusions is higher than $\mathrm{NbC}$ inclusions in the plateau regime and TiN inclusions start to progressively fail at a lower stress level than $\mathrm{NbC}$.

\subsubsection{VHCF Lifetime of the pre-damaged specimens}

Pre-damaged VHCF specimens were tested under the same testing conditions than the as-received VHCF specimens. The lifetimes of predamaged VHCF specimens were directly compared to the previous results obtained from as-received VHCF specimens, as depicted in Fig. 12. Lifetimes for pre-strained specimens were substantially shorter than for microindented specimens. PAN-2 and PAN-4 exhibit similar VHCF lifetime regardless of whether prior damage was introduced. Interestingly, prior damage introduction strongly affected the PAN-6 VHCF lifetime. PAN-6 VHCF specimens pre-damaged by the tensile loading failed with lifetimes that were significantly shorter compared to the as-received microstructure. In the case of PAN-6 specimens predamaged by microindentation under loading, the discrepancy in lifetime is relatively high. One specimen failed around $5 \times 10^{6}$ cycles, i.e. in the scatter of PAN-2 and PAN-4 VHCF lifetime, while a second specimen failed for a two-order-of-magnitude-higher number of cycles $\left(2.3 \times 10^{8}\right.$ cycles). This particular difference in lifetime will be discussed in the following parts of the document. VHCF lifetimes on predamaged specimens are reported in Table 2.

Table 2

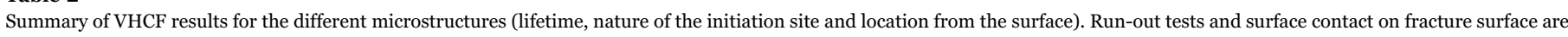
denoted $\mathrm{RO}$ and $\mathrm{SC}^{*}$ in the table, respectively.

\begin{tabular}{|c|c|c|c|c|c|c|}
\hline Condition & Reference & $\varepsilon_{\max }(\%)$ & $N_{f}\left(10^{6}\right)$ & Nature of the initiation site & Size of the initiation site $(\mu \mathrm{m})$ & Location $(\mu \mathrm{m})$ \\
\hline \multirow[t]{9}{*}{ As-Received } & $2 \mathrm{~A} 2$ & 0.20 & 11.0 & Cluster TiN & 39.3 & 40 \\
\hline & $2 \mathrm{~A} 3$ & 0.22 & 4.0 & TiN & 12.0 & 0 \\
\hline & $2 \mathrm{~A} 4$ & 0.22 & 3.9 & TiN & 13.2 & 10 \\
\hline & $4 \mathrm{~A} 2$ & 0.22 & 2.0 & Grain & 26.8 & 10 \\
\hline & $4 \mathrm{~A} 3$ & 0.22 & 2.6 & Grain & 22.4 & 0 \\
\hline & $4 \mathrm{~A} 4$ & 0.22 & 4.8 & Cluster NbC & 31.8 & $<50$ \\
\hline & $6 \mathrm{~A} 2$ & 0.22 & 250.0 (RO) & - & - & - \\
\hline & $6 \mathrm{~A} 3$ & 0.22 & 250.0 (RO) & - & - & - \\
\hline & $6 \mathrm{~A} 4$ & 0.22 & $1000.0(\mathrm{RO})$ & - & - & - \\
\hline \multirow[t]{9}{*}{ Tensile } & $2 \mathrm{~A} 1$ & 0.22 & 3.8 & NbC-TiN & 24.0 & 0 \\
\hline & $2 \mathrm{~B} 1$ & 0.22 & 6.2 & $\mathrm{SC}^{*}$ & - & $<30$ \\
\hline & $2 \mathrm{~B} 2$ & 0.22 & 5.5 & Cluster NbC & 23.2 & 15 \\
\hline & $4 \mathrm{~A} 1$ & 0.22 & 2.3 & $\mathrm{TiN}$ & 16.4 & $0-35$ \\
\hline & $4 \mathrm{~B} 1$ & 0.22 & 4.0 & $\mathrm{TiN}$ & 12.1 & $<50$ \\
\hline & $4 \mathrm{~B} 2$ & 0.22 & 3.9 & $\mathrm{TiN}$ & 16.1 & 0 \\
\hline & $6 \mathrm{~A} 1$ & 0.22 & 19.9 & TiN & 15.7 & 5 \\
\hline & $6 \mathrm{~B} 1$ & 0.22 & 9.0 & Grain & 18.7 & 0 \\
\hline & $6 \mathrm{~B} 2$ & 0.22 & 3.7 & Cluster NbC & 36.2 & 0 \\
\hline \multirow[t]{6}{*}{ Microindentation } & $2 \mathrm{~B} 3$ & 0.22 & 7.1 & $\mathrm{SC}^{*}$ & - & $<50$ \\
\hline & $2 \mathrm{~B} 4$ & 0.22 & 9.0 & TiN & 15.1 & 0 \\
\hline & $4 \mathrm{~B} 3$ & 0.22 & 5.7 & Cluster TiN & 25.7 & 10 \\
\hline & $4 \mathrm{~B} 4$ & 0.22 & 9.8 & TiN & 15.7 & 0 \\
\hline & $6 \mathrm{~B} 3$ & 0.22 & 229.5 & $\mathrm{SC}^{*}$ & - & 0 \\
\hline & $6 \mathrm{~B} 4$ & 0.22 & 5.1 & TiN & 14.8 & 0 \\
\hline
\end{tabular}



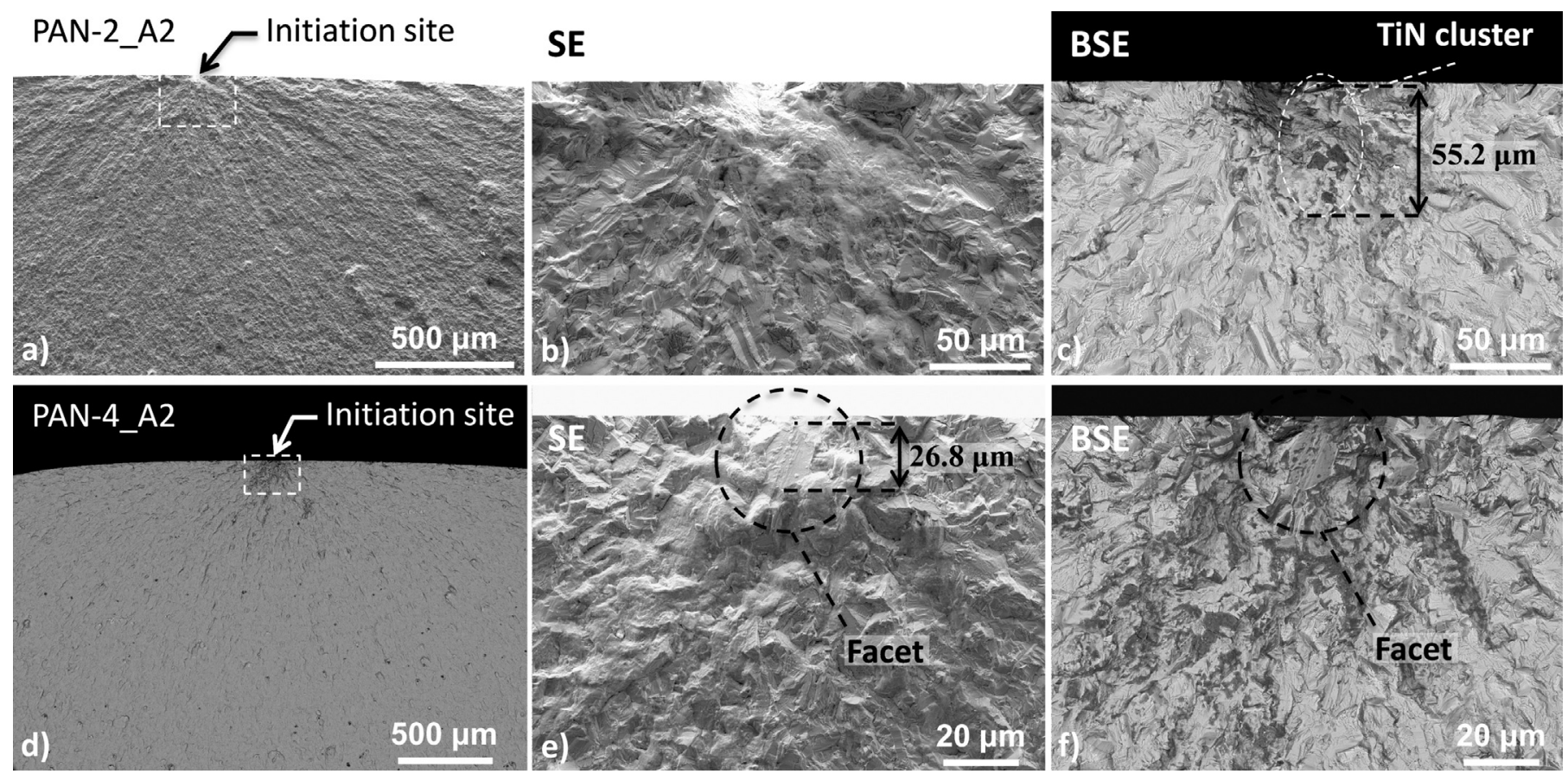

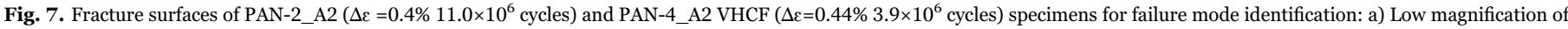

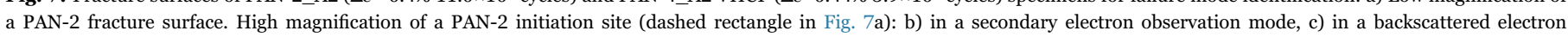

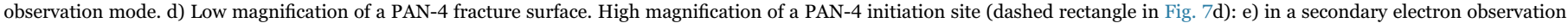
mode, $\mathrm{f}$ ) in a backscattered electron observation mode.

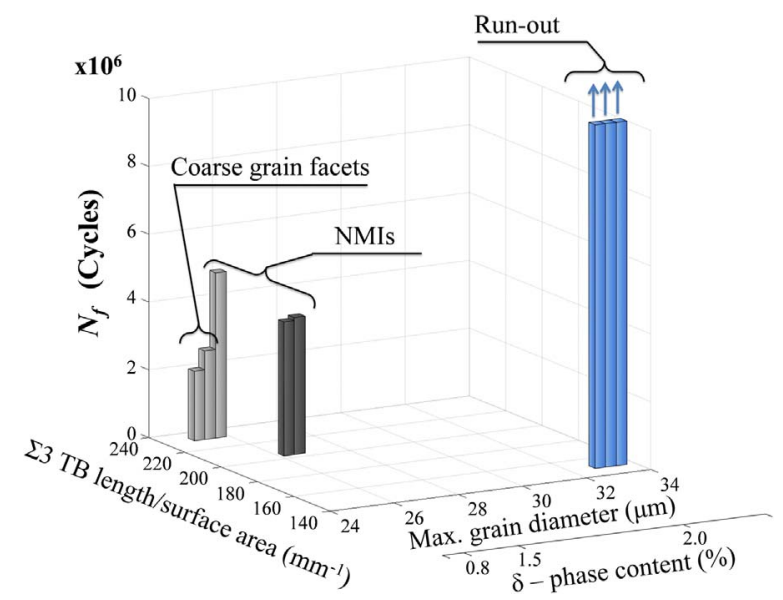

Fig. 8. VHCF lifetime for the different pancakes in relation with microstructural features (as received VHCF specimens). Arrows correspond to run-out tests.

\subsubsection{Fracture surface analysis}

Fractographic observations of the specimens were performed to identify crack initiation sites. As observed for the as-received specimens, surface or near-surface $(<50 \mu \mathrm{m})$ initiation sites were observed for all the pre-damaged specimens, for all microstructures and predamage procedures. For cracks introduced by microindentation under loading, none of the pre-indented NMIs led to macroscopic fracture. Unfortunately, no PAN-6 fracture surfaces were clean enough to confirm the failure mode for pre-damage introduced by microindentation under loading, i.e. within a grain or a NMI. Thus, the high difference in lifetime for both PAN-6 specimens could not be explained via fractographic observations. Failure within sub-surface NMIs (cluster of nitrides) was observed for the PAN-4 microstructure (Fig. 13). Since cracks mostly initiate in the surface/sub-surface regions of the specimen, observations of the gage area aimed to provide supplementary information when fracture surfaces remains difficult to analyze. Debonding of some NMIs was identified via gage surface observations

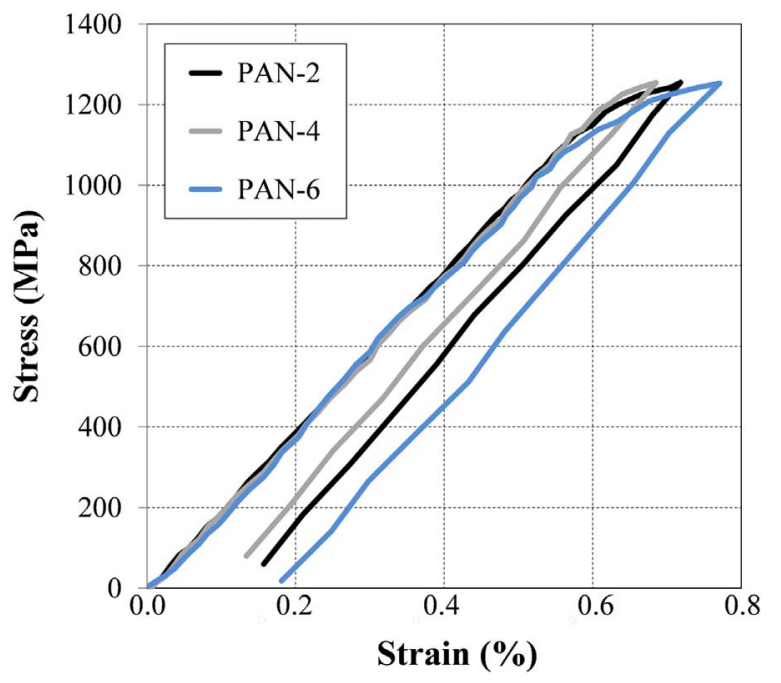

Fig. 9. Tensile behavior of the different microstructures along the tangential direction at room temperature interrupted at $1250 \mathrm{MPa}$.

before failure, resulting in a geometrical cavity along the crack (Fig. 14). This geometrical cavity is located in the region where the crack is more open, indicating the proximity of the crack initiation site. For VHCF specimens pre-damaged by prior tensile loading, fracture generally occurred due to cleavage of NMIs. Fig. 15 illustrates different examples of fractures for the three microstructures investigated. The fatal crack generally initiated within coarse carbonitrides, cluster of nitrides or even within an isolated nitride. A summary of fractographic observations is reported in Table 2.

\subsubsection{Crack initiation observations}

Small cracks were present far from the macroscopic failure, for both pre-damage procedures while a single initiation site was found for "asreceived" microstructures. Interrupted VHCF tests were conducted for both pre-damage procedures on the three microstructures. The object 

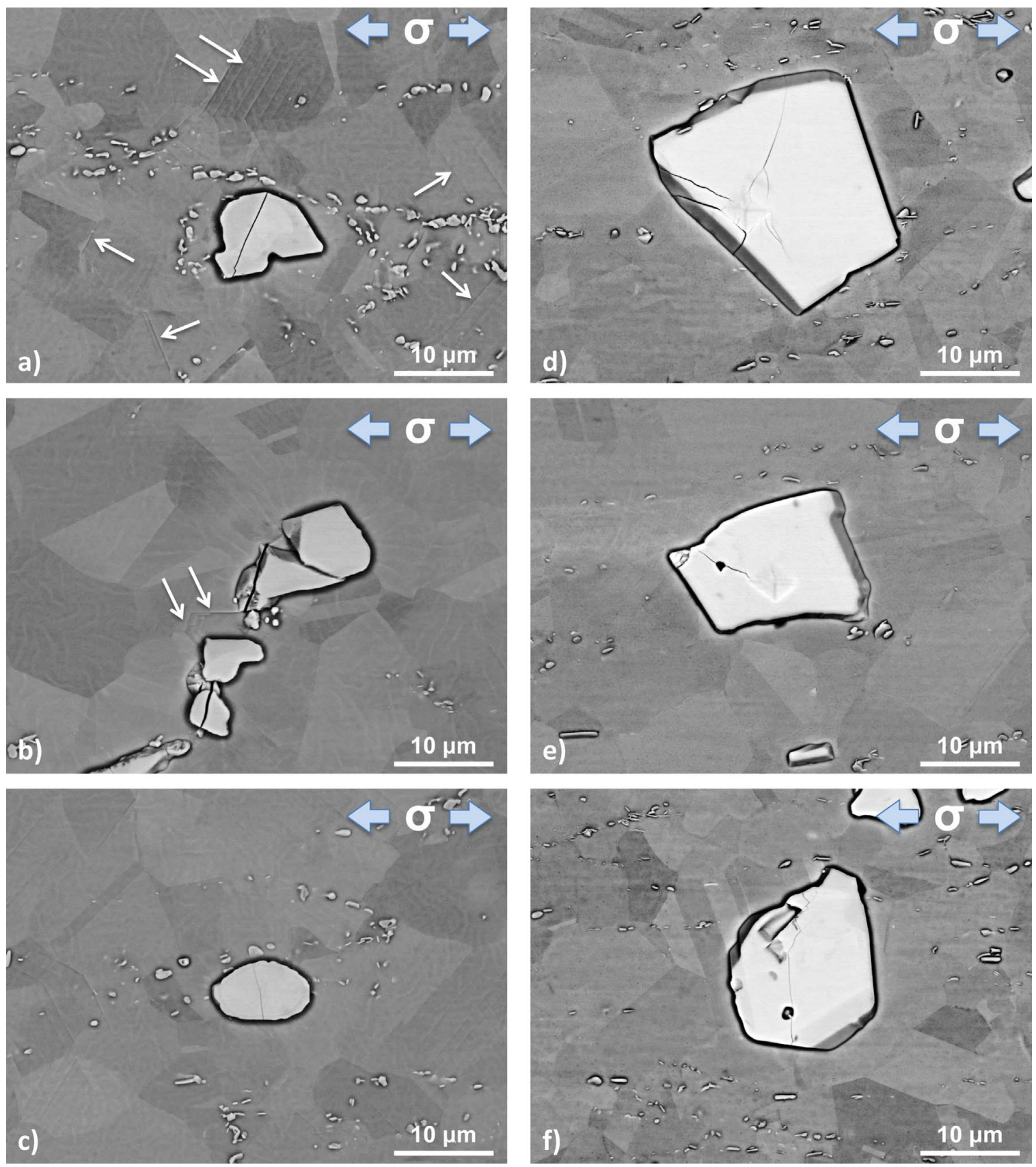

Fig. 10. Examples of pre-damaged NMIs by interrupted tensile tests (a, b, c) and microindentation (d, e, f).

was to track twenty to thirty pre-damaged NMIs along the entire gage area per conditions for different numbers of cycles up to failure. Interestingly, pre-straining specimens in the macroscopic plastic regime promotes small crack propagation (at least one grain in length) from pre-damaged NMIs in comparison to the microindentation procedure (Fig. 16), which does not necessarily lead to crack extension into the base material. Most of the small cracks grow during the first million of cycles and do not propagate more than one grain in length. As depicted in Fig. 17, small cracks occurred either within the metallic matrix or from NMIs.

EBSD characterization of small cracks initiated within the metallic matrix (Fig. 18a and b) was performed in order to identify parameters that favor crack initiation. As depicted in Fig. 17a, b, e and f, cracks initiated parallel to and closely offset from ( $\Sigma 3)$ twin boundaries, in good agreement with Miao et al. [18,19] and Stinville et al. [15]. Interestingly, grains on either side of the cracked twin boundary exhibit a high difference in Young's modulus along the horizontal direction, i.e. the loading direction (Fig. 17c and g). In addition to this, these twins and parent grains all exhibited high Schmid factors ( $>0.44$ ) for a slip system parallel to the twin boundary in reference to the loading direction. They are, then, oriented favorably to develop single slip $[15,34]$.

\section{Discussion}

Crack initiation modes of a DA718 superalloy were examined at room temperature in the very high cycle fatigue regime. Different microstructures were purposely forged to evaluate the effect of nonmetallic inclusions on the crack initiation sensitivity in the VHCF regime according to the microstructure. In this low strain/stress amplitude regime, failures from microstructural heterogeneities such as coarse NMIs or clusters and failure near twin boundaries from large 


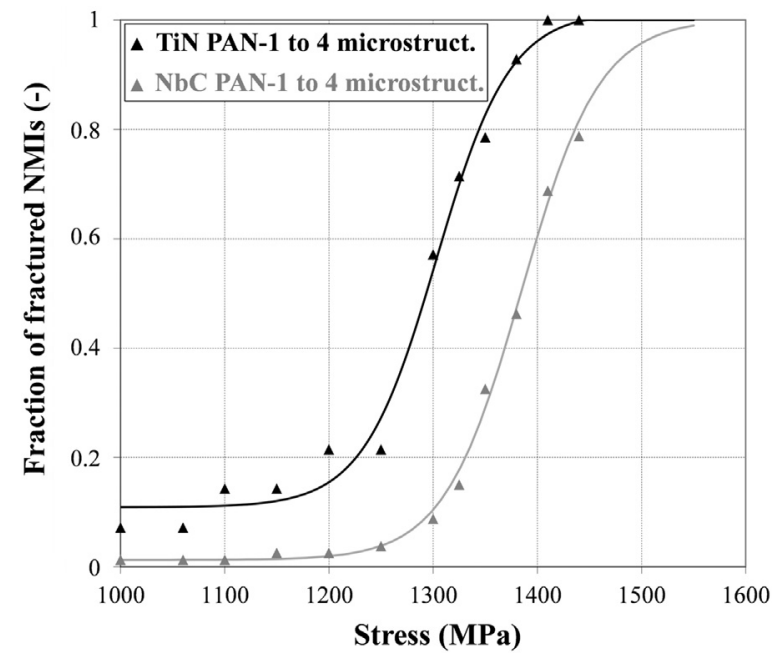

Fig. 11. Fraction of fractured NMIs as a function of the monotonic tensile stress level for an alloy DA718 microstructure similar to PAN-1 \& 2 and PAN-3 \& 4 microstructures.

favorably oriented grains were observed (Fig. 7). Crack initiation at such heterogeneities has been reported in the literature for several materials in this low cyclic stress regime [15-25] and associated with the irreversibility of the deformation. Elastic anisotropy at the grain scale, especially in the vicinity of twin boundaries $[15,18,28,35]$, or high differences in elastic properties between inclusions and the metallic matrix [36-39] is observed to influence the initiation processes. Due to microstructure heterogeneities, local stresses can be sufficiently high to introduce localized plastic deformation that ultimately leads to crack initiation under cyclic stresses. For the IN718 superalloy, the complex relationship between IN718 microstructures and the nature of the initiation site has not been clearly documented in the low strain/stress regime [20-25]. In the present study, this relation has been studied by investigating different microstructures obtained from various forging processes.

The present work shows that coarser grain microstructures (PAN-5 \&6) exhibited a higher fatigue life under VHCF in the "as-received" condition (Figs. 6 and 8 and Table 2). For finer grain microstructures (PAN-1 \& 2 and PAN-3\&4), a higher occurrence of twin boundaries density made DA718 alloy more sensitive to crack initiation adjacent to twin boundaries while low twin containing DA718 alloy was shown to fail within TiN inclusions (Fig. 7 and Table 2). It is worth mentioning that high $\Sigma 3$ twin containing microstructures ( $\Sigma 3$ twin length per surface area $\geq 235 \mathrm{~mm}^{-1}$ ) exhibit relatively high probability of fracture under such VHCF conditions, favoring crack initiation close to large twin boundaries. The relatively high elastic anisotropy in the superalloys and the strong elastic differences between the superalloys matrix and NMIs favor both the crack initiation mechanisms due to local stress concentration within brittle NMIs or at large twin boundaries.

Pre-straining of specimens and local damage introduction by microindentation led to some modifications in crack initiation mechanisms and lifetime. The probability of failure within brittle NMIs increased using both methods for introduction of damage (Figs. 1216 and Table 2).

Pre-straining of specimens aimed to pre-cracked a certain fraction of NMIs but also to promote strain localization at slip bands and in the vicinity of cracked NMIs (Fig. 10). As a result, pre-straining of specimens was shown to substantially shorten VHCF life of the "coarse grain" microstructure (PAN-5\&6 in Fig. 12), leading to fatigue life comparable to the other microstructures. This result is in contradiction with the fact that grain boundaries act as a microstructural barrier for short crack propagation [40].

In addition, only a small fraction of pre-cracked NMIs induced small crack propagation. Surprisingly, none of the cracks within NMIs introduced by microindentation propagate in the surrounding grains. Therefore, a pre-cracked NMI (which in some instances could occur during processing) is not a sufficient criterion for failure. It follows that the neighborhood (grain orientation, local plasticity) around the NMIs plays a significant role in the propagation of the crack from the NMIs to the superalloy.

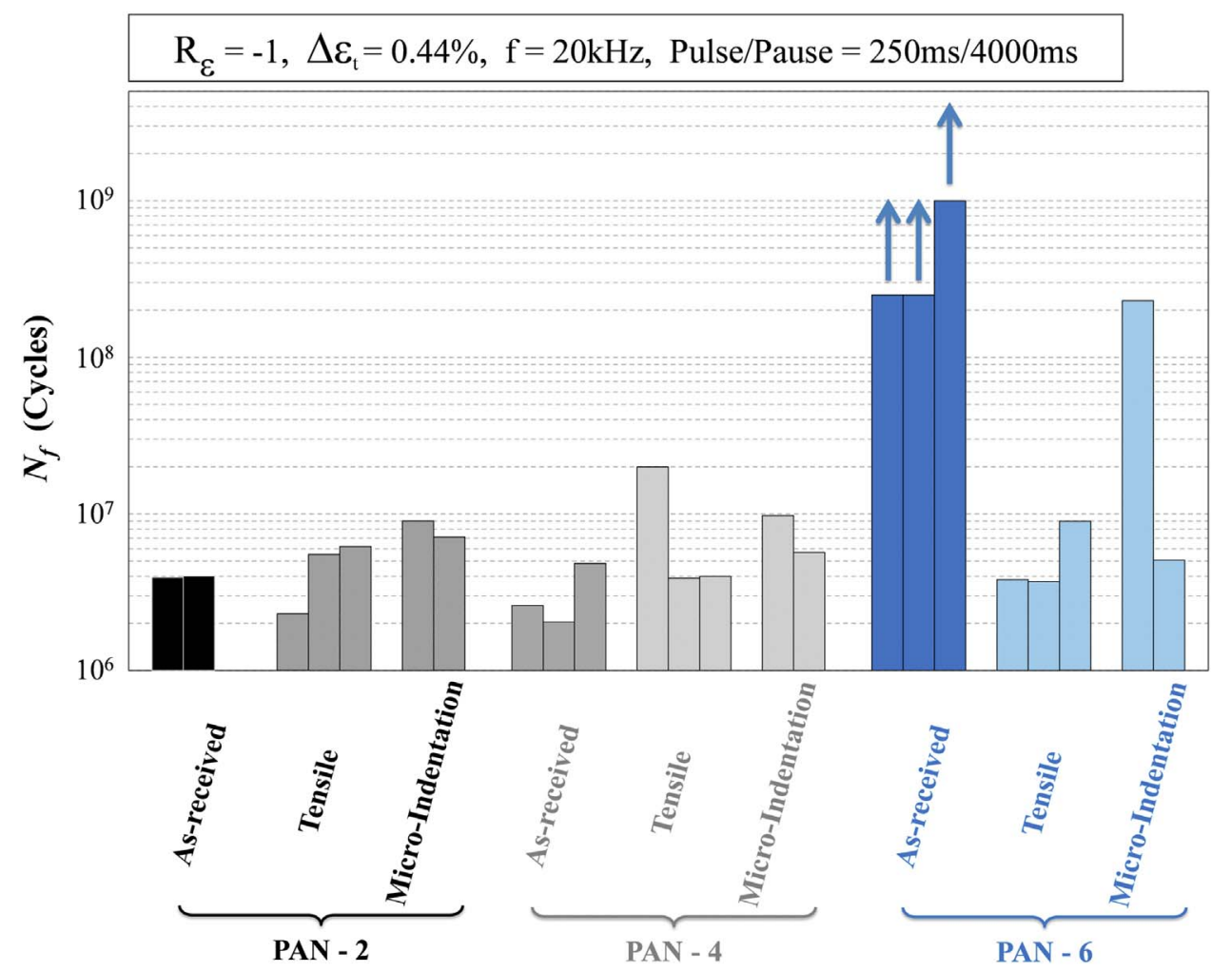

Fig. 12. VHCF lifetime for the different pancakes with and without prior damage introduction. Arrows correspond to run-out tests. 

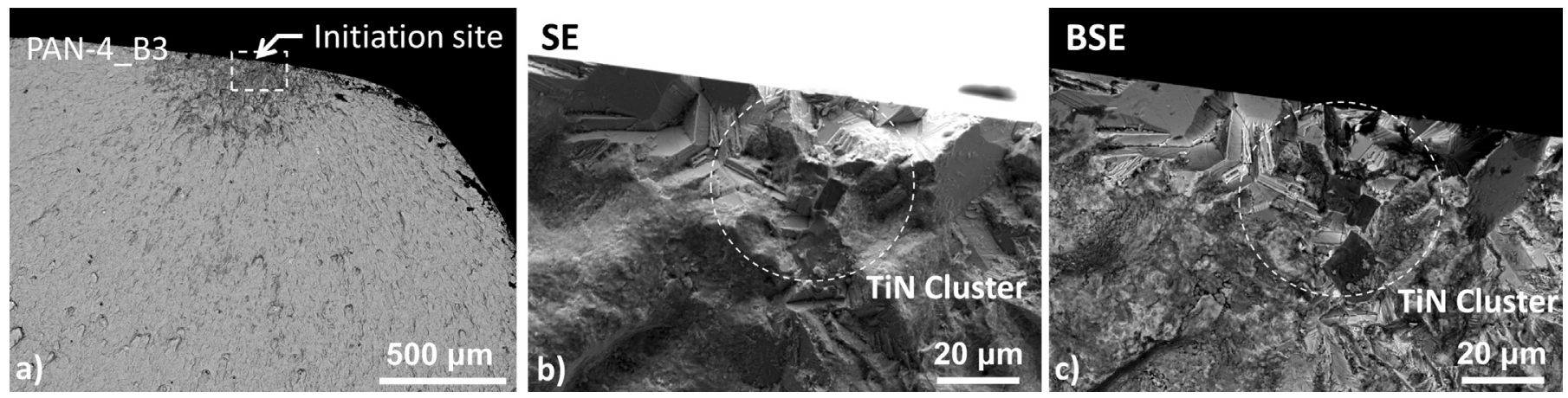

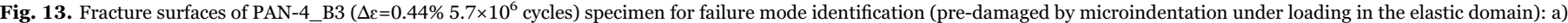

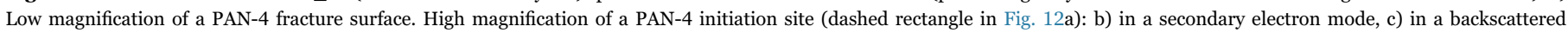
electron mode.

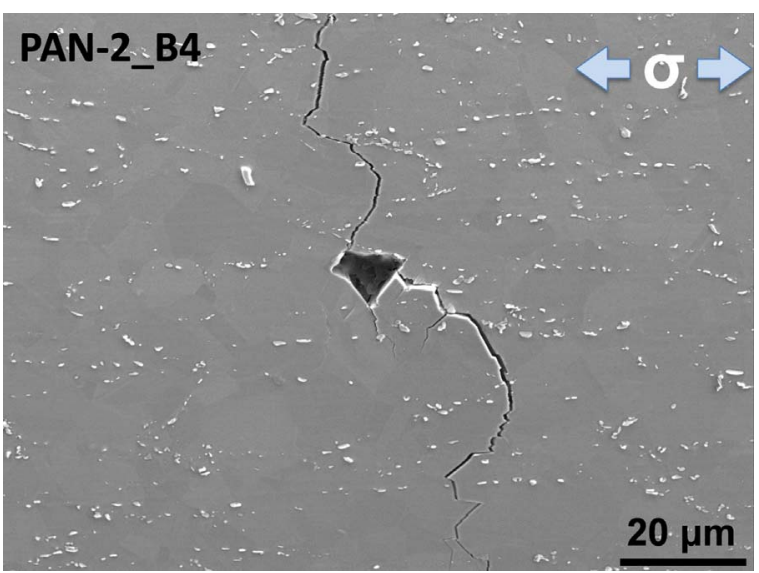

Fig. 14. Debonding of a TiN inclusion responsible of the fracture of PAN-2_B4 specimen $\left(\Delta \varepsilon=0.44 \% 9.0 \times 10^{6}\right.$ cycles $)$.

In the following sections, the role of microstructural features that control the lifetime and the nature of initiation site will be discussed.

\subsection{VHCF failure modes on as-received microstructures}

4.1.1. VHCF crack initiation within coarse grain/at twin boundaries

For high twin containing DA718, cracks preferentially initiate within coarse grains at the high end of the size distribution and potentially along twin boundaries (Fig. 7d, e and f). Stress concentrations were found with different intensities close to grain boundaries. In fcc materials having relatively high Zener anisotropy ratio, such as Nibased superalloys, high incompatibility stresses were shown to be responsible of crack initiation under cyclic stresses in the macroscopic elastic regime [15,28-30,35]. Twins experience higher stress concentrations compared to other types of grain boundaries due to a particular crystal symmetry on either side of the twin boundary $[18,28,29,41]$. Digital image correlation has demonstrated that enhanced strains are present in the low elastic modulus twin adjacent to a high elastic modulus parent grain within high Schmid factor loaded grains [15]. Furthermore, Stinville et al. recently defined microstructural criteria for crack initiation under VHCF conditions in a high twin density powder metallurgy superalloy [15]. This statistical approach outlined via a crack density function the necessity of high elastic modulus differences between the twin and the parent grain to initiate cracks close to a large twin boundary parallel to a slip system having a high Schmid factor in reference to the macroscopic loading direction.

\subsubsection{VHCF crack initiation within nitrides and cluster of nitrides}

Fine grain and low twin containing DA718 failed under VHCF conditions due to crack initiation within large titanium nitrides inclusions or clusters of titanium nitrides inclusions (Fig. $7 \mathrm{a}, \mathrm{b}$ and c). High cycle fatigue and low cycle fatigue studies performed on Alloy 718 both highlighted the sensitivity of crack initiation at NMIs when grains are as fine or even finer than non-metallic inclusions present in wrought nickel-based superalloys, especially at low temperature [3$7,42]$. Cleavage of surface or near-surface NMIs generally leads to failure at room temperature for ASTM 10 and finer grain Alloy 718 microstructures at relatively high stress levels within the macroscopic elastic regime. At lower cyclic stress amplitude, e.g. in the VHCF regime, coarse internal defects such as NMIs were responsible for failure [16-20,43-45]. In wrought Alloy 718, the coarsest "defects" designated as non-metallic inclusions (NMIs) in this paper - are generally considered to be carbides, nitrides or carbonitrides [46]. In the low stress/strain regime, elastic properties at the grain scale are of major interest especially for heterogeneous and multiphase materials. Experimental or theoretical elastic constants of nickel-based superalloys, niobium carbides and titanium nitrides were reported in Table 3 [31-33]. According to its A1-fcc crystallographic structure, the $\gamma$ metallic matrix of IN718 exhibits the weakest and highest elastic moduli along $<001>$ and $<111>$ crystallographic directions, respectively. Inversely, the B1-cubic of TiN and NbC confers the weakest and highest elastic responses along $\langle 111\rangle$ and $<001>$ crystallographic directions. Young's moduli range from 124 to $318 \mathrm{GPa}, 417-$ $556 \mathrm{GPa}$ and 416-579 GPa for the metallic matrix Alloy 718, TiN and $\mathrm{NbC}$ respectively. Finite element calculations demonstrate the detrimental effects of non-metallic inclusions under cyclic loading due to cumulative plastic deformation at the interface leading to debonding of the NMI/metallic interface or microfracture within NMIs [36-39].

Despite similar elastic properties between nitrides and carbides, fractographic analyses only evidenced regions rich in titanium nitrides in an isolated form or in a cluster form to act as favorite site for crack initiation. Interestingly, in-situ tensile tests conducted on an Alloy 718 with a microstructure comparable to PAN-1 \& 2 and PAN-3 \& 4 microstructures highlight the lower resistance of TiN inclusions in comparison with $\mathrm{NbC}$ carbides under monotonic stress, especially at the transition of the macroscopic elastic/plastic behavior (Fig. 11). TiN inclusions have a particularly sharp and geometrical (squared, rectangular or hexagonal) morphology [47] while $\mathrm{NbC}$ inclusions have much more random and more rounded morphology (Figs. 10 and 17). Some coarse $\mathrm{NbC}$ inclusions have a blocky morphology but are present in a minor proportion (Fig. 10d, e and f). This sharp and blocky morphology is conferred by the none-restrictive growth due to diffusive supply of $\mathrm{Ti}$ and $\mathrm{N}$ from the surrounding liquid metal during the solidification process [47-49]. EBSD investigations were conducted and aimed to evidence $(001)_{\text {TiN }}$ planes as solidification front whatever the orientation of the TiN inclusions and the surrounding grains (Fig. 19). TiN inclusions are thought to have a cubic shape with (001) faces and < $001>$ edges, i.e. the stiffest directions in B1-cubic structures. Therefore, tensile stress concentrations within TiN inclusions are 

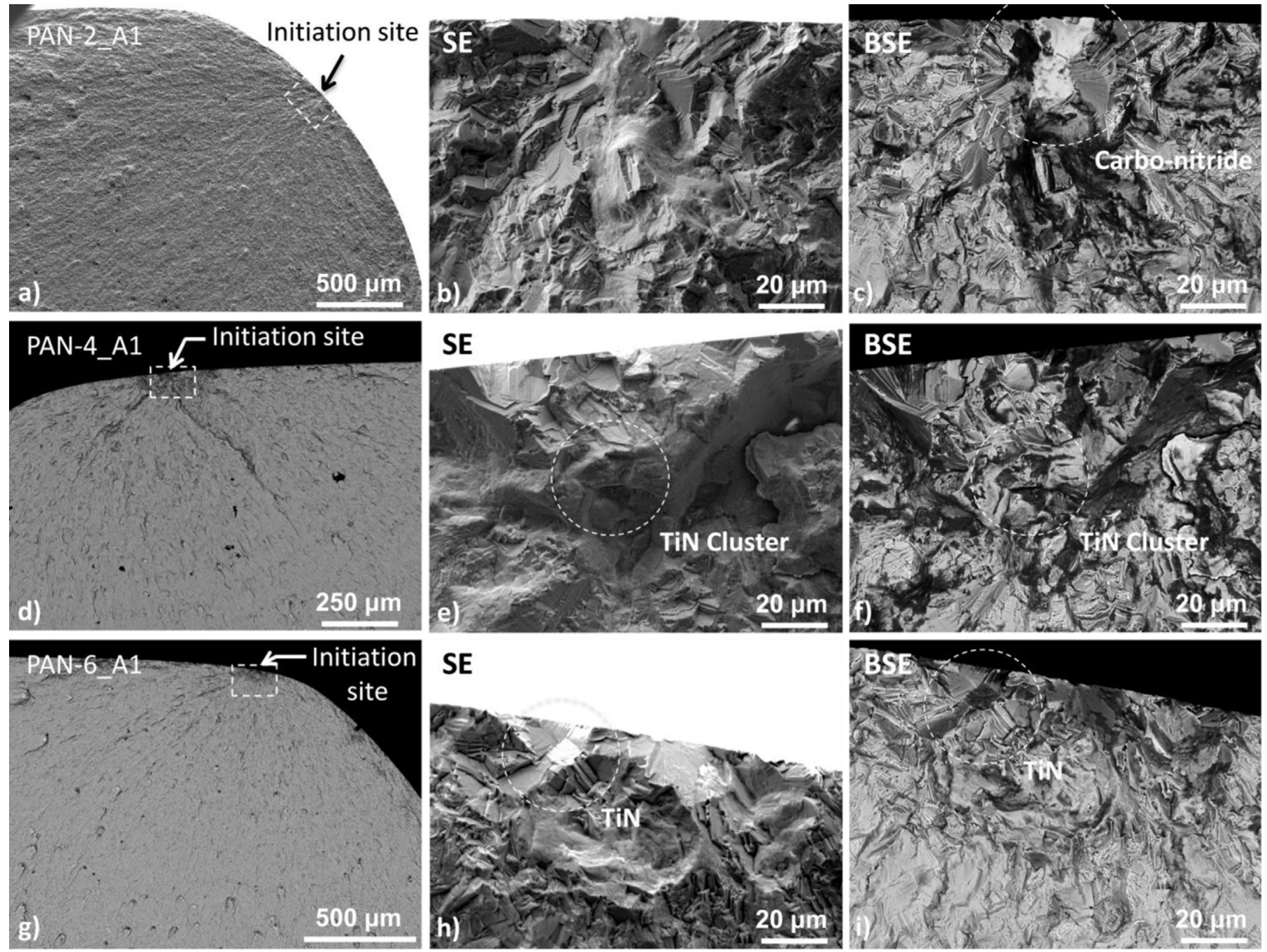

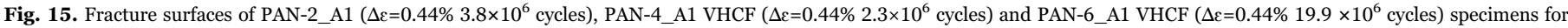

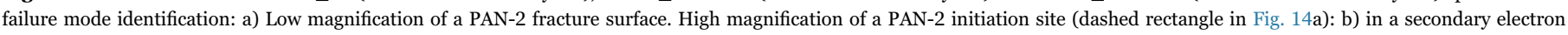

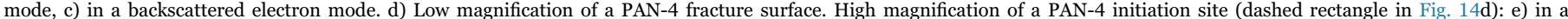

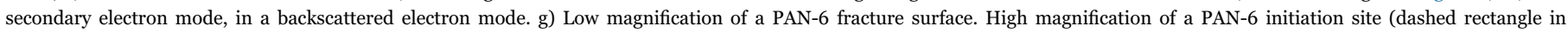
Fig. 14g): h) in a secondary electron mode, i) in a backscattered electron mode. Specimens were pre-strained in the plastic domain before VHCF testing.

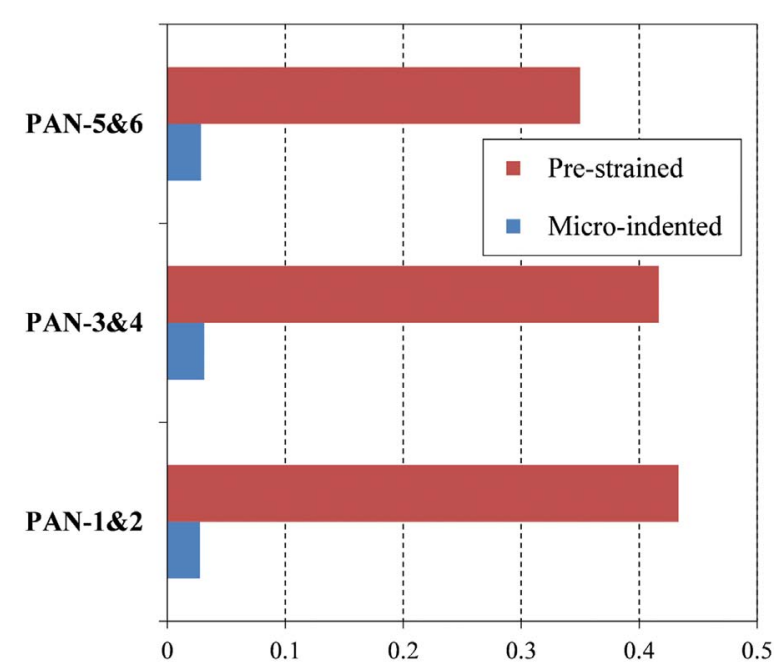

Fraction of crack propagating from pre-cracked NMIs (-)

Fig. 16. Effect of the pre-damage introduction procedure on the fraction of small cracks propagating from pre-cracked NMIs. believed to be maximal due to these crystallographic specifications since the surrounding metallic matrix is softer than TiN inclusion whatever the grain/inclusion orientations. In addition, (001) planes are preferential planes for cleavage in B1-cubic crystallographic structures..

\subsection{VHCF behavior of pre-damaged microstructures}

Two pre-damaging conditions were investigated, i.e. pre-straining specimens in the plastic domain and microindenting NMIs under tensile loading in the macroscopic elastic domain. Damage introduction prior to VHCF tests were shown to have a significant effect on the fatigue life for the coarsest microstructure (PAN-5 \& 6). It was observed that for the two finest microstructures investigated pre-cracked NMIs do not lead to shorter fatigue life. Moreover, NMIs, in the form of isolated inclusion or clusters, are found to be as detrimental as TB in favorable crystallographic conditions (Figs. 12-15 and Table 2).

Fractographic analyses evidenced that cleavage of NMIs at the surface and at the near-surface region, in an isolated form or in clusters, (Figs. 12 and 14 and Table 2) and NMIs debonding (Figs. 13 and 16d) were at the origin of most of the macroscopic cracks of predamaged specimens (Figs. 12-14). None of the pre-indented NMIs 

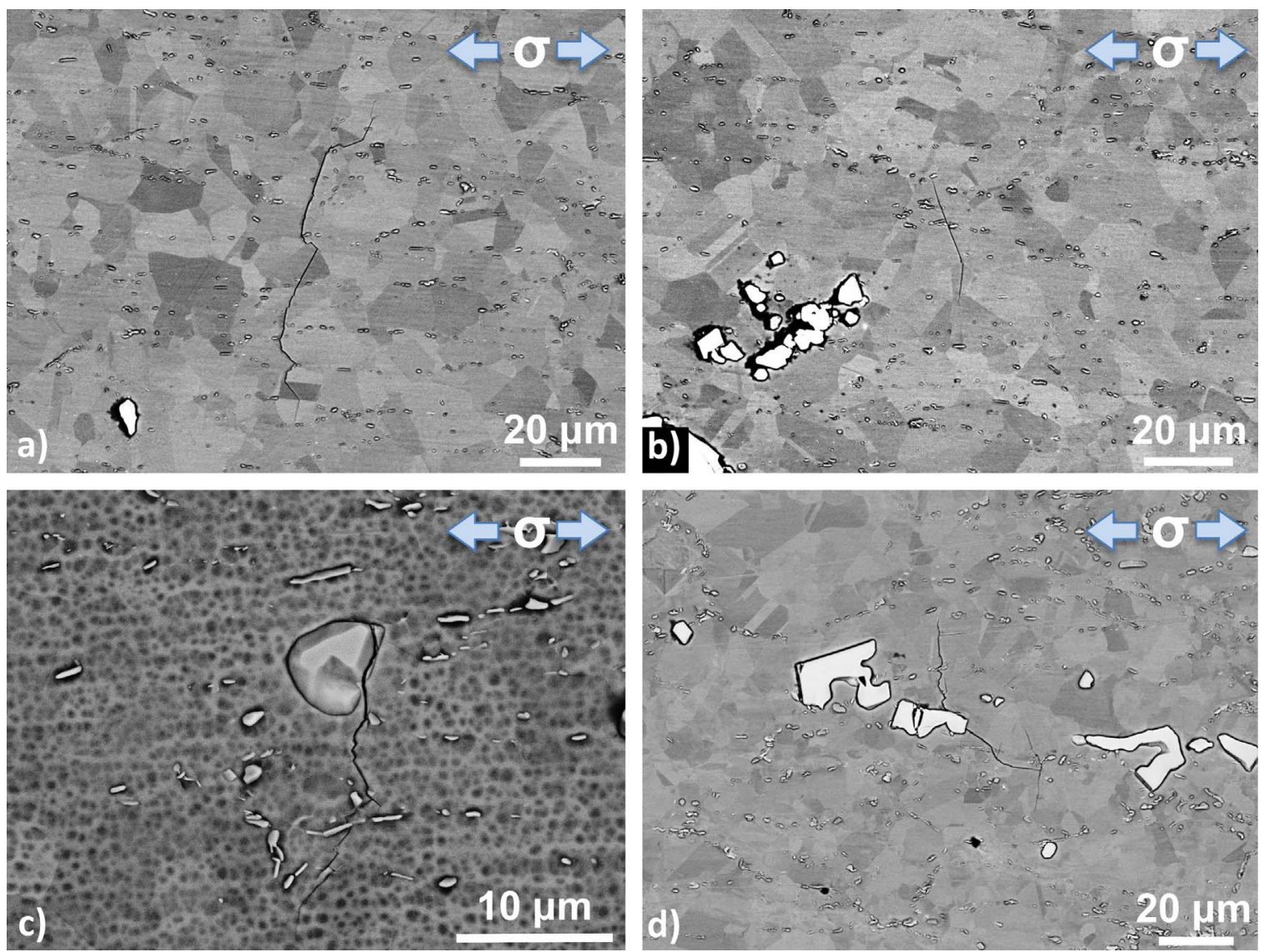

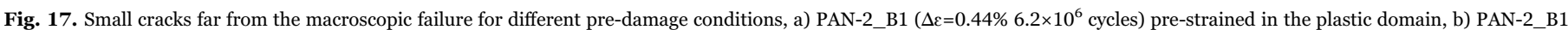

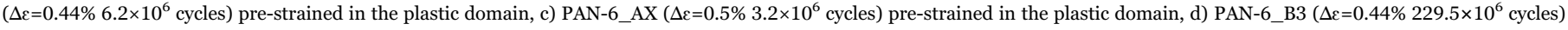
pre-damaged by microindentation under loading in the elastic domain.

leads to the final fracture under this particular VHCF condition. Therefore, the way the NMI is cracked and/or the local plasticity in the surrounding grains are parameters affecting the short crack propagation from pre-cracked NMIs into the metallic matrix. In-situ tensile tests recently demonstrate difficulties in damage transfer from cracked NMIs to the neighborhood under monotonic loading [3]. Finite element analyses of inclusions within metallic matrix were investigated in the literature with different damage configurations, i.e. cohesive inclusion/matrix interface, partially debonded inclusions and cracked inclusions [36,39]. These studies demonstrated the detrimental effect of hard and brittle inclusions in materials subjected to cyclic loadings. Moreover, partially debonded non-metallic inclusions were observed to be more damaging than other configurations [36,39].

Secondary cracks were, observed at the surface of the gage area in the vicinity of NMIs and close to $\Sigma 3$ TB far from the macroscopic crack. This point is discussed in the following sections.

\subsubsection{VHCF crack initiation within NMIs}

Pre-straining of coarse microstructure specimens prior to VHCF tests considerably shortens the lifetime in comparison to the "asreceived" specimens $\left(3 \times 10^{6}\right.$ to $2 \times 10^{7}$ cycles instead of run-out tests, see Fig. 12). Despite the fact that pre-straining increases the macroscopic yield stress, some highly pre-deformed materials (between 2$10 \%$ plastic strain) experience a significant reduction in low-strainfatigue life due to the development of tensile mean stresses during fatigue loading [50] or due to pronounced roughening leading to an increase of the notch sensitivity [51,52]. In the present work, prestraining of the specimens consisted of application of a residual plastic strains ranging from $0.09 \%$ to $0.18 \%$ according to the microstructure, with deformation levels considerably lower than in references [51,52].
However, plasticity is confined in the vicinity of cracked NMIs and was shown to induce roughening due to the activation of several slip systems (Fig. 10b). Such local plasticity was recently reported via insitu tensile experiments on different DA718 microstructures [3]. In addition, VHCF interrupted tests pointed out the fact that small cracks propagates from pre-cracked NMIs in tension with local plasticity in the grains adjacent to the crack tips.

In the case of specimens pre-damaged by microhardness under uniaxial elastic loading, the coarse grain microstructure was shown to exhibit a high variability in fatigue life (Fig. 12). Furthermore, interrupted VHCF tests show that cracks did not propagate from crack-indented NMIs (Fig. 16) and none of the pre-indented NMIs lead to the macroscopic failure of the specimen. Different cases of precracked inclusions after pre-damage introduction were depicted in Fig. 10d, e and f. Cleavage of the NMIs was shown to be slightly different from the one encountered with the plastic pre-straining procedure and results sometimes in multiple cracks (Fig. 10d) or in none-transverse cracks (Fig. 10e). At $800 \mathrm{MPa}$, the uniaxial loading was sufficient to crack few surface carbides or nitrides (about $0.6 \%$ of the observed carbides) prior to VHCF tests (Fig. 10f). Under such a prestraining condition, DA718 alloy is stressed in the macroscopic elastic regime. For this reason, the development of tensile mean stresses reported in ref. [50] might not be applicable for this pre-damaging procedure. However, those pre-cracked NMIs, according to their low occurrence and their neighborhood could potentially induce crack propagation with different growth rates, leading to a certain scatter in VHCF lifetime (Fig. 12 and Table 2). Therefore, the local plasticity and the local roughness in the crack tip region of pre-cracked NMIs are strongly believed to favor small crack propagation under VHCF conditions. 

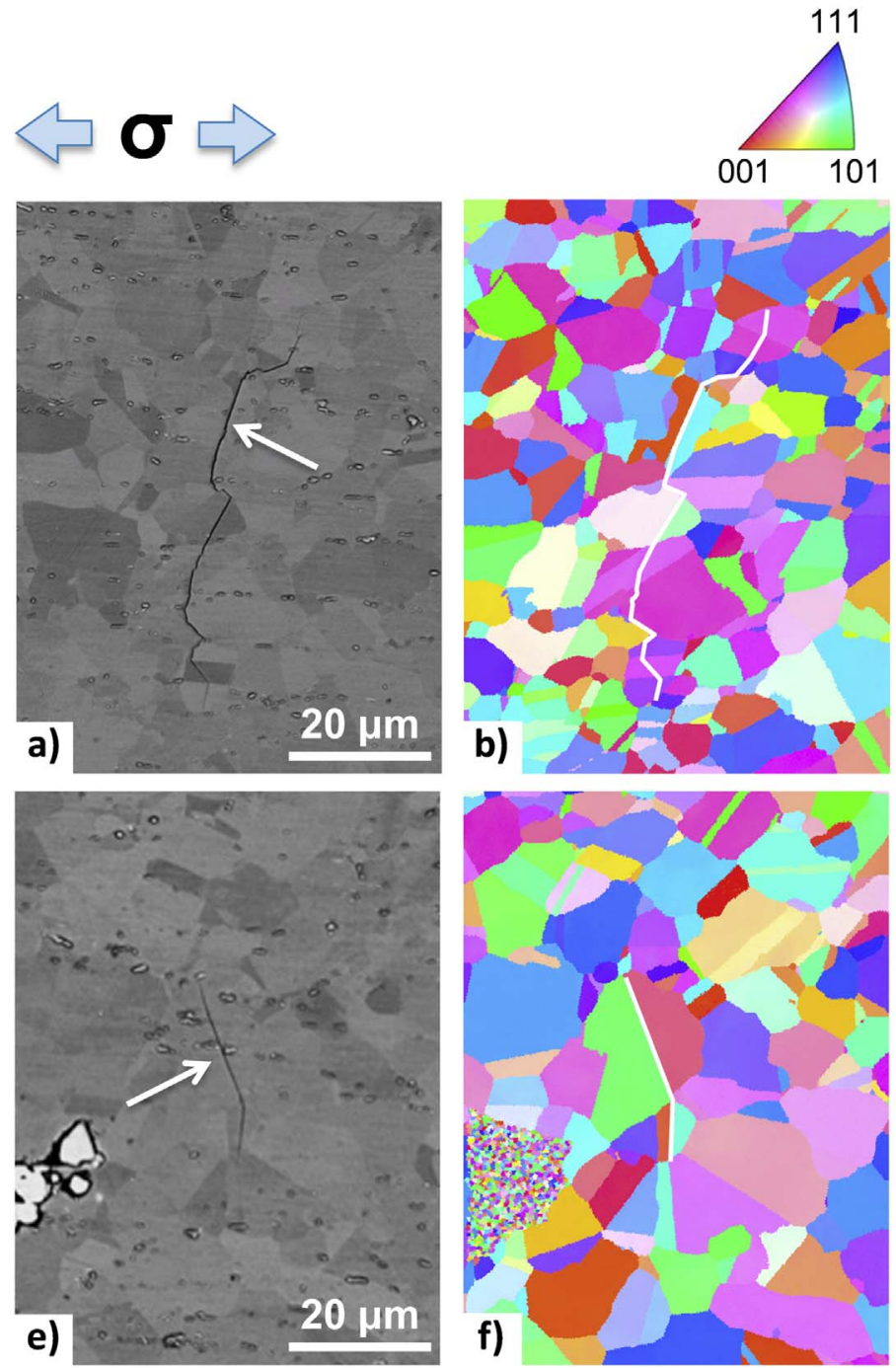

124

Elastic moduli $/ l$
loading dir.
(GPa)
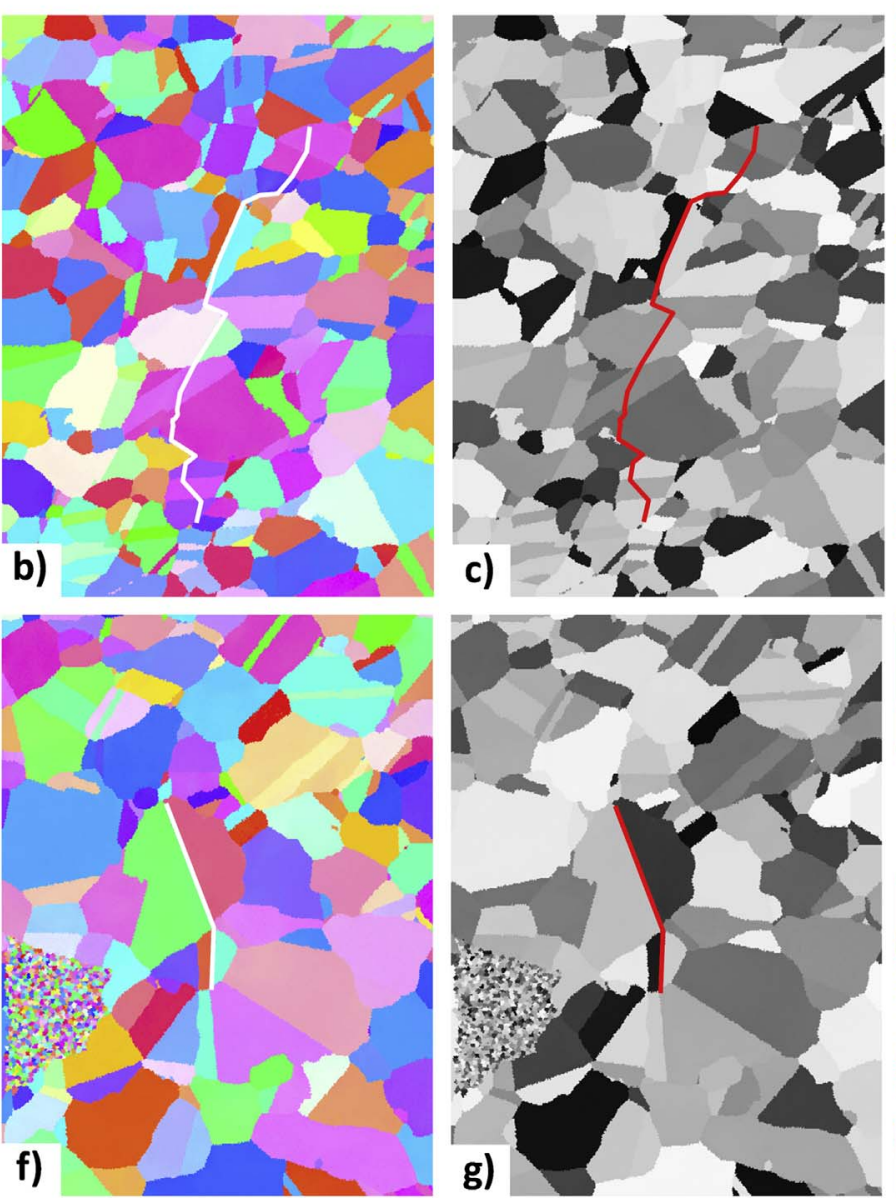

Max Schmid factor /I loading dir.

$318 \quad 0.44$ 0.5
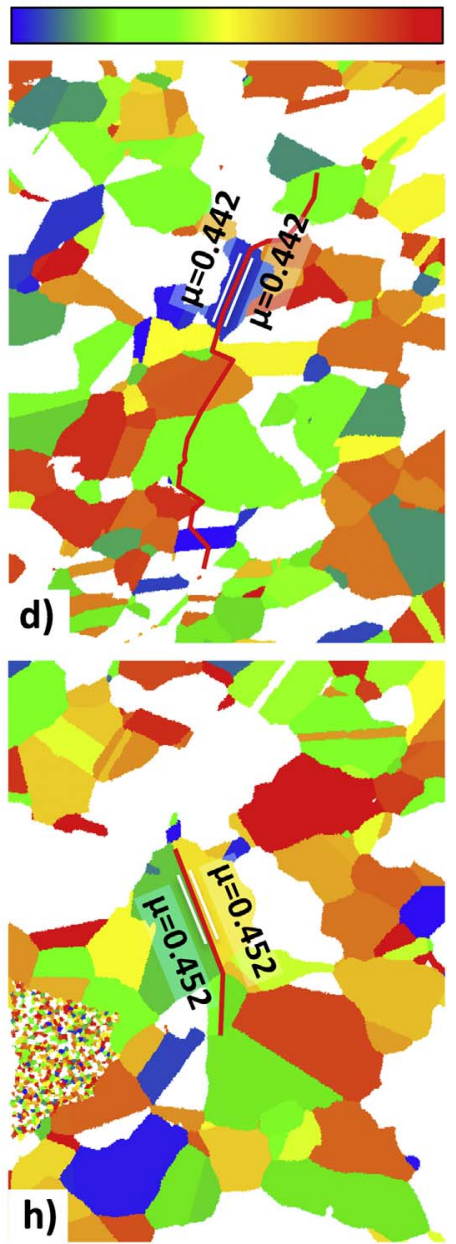

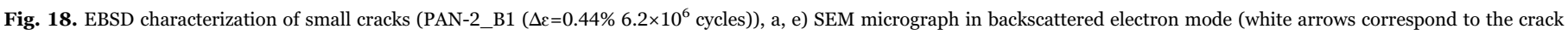

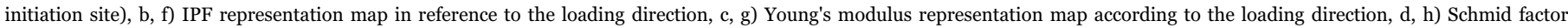
representation map according to the loading direction (White grains have Schmid factors below 0.44).

\subsubsection{Secondary cracks close to $\Sigma 3 T B$}

Small secondary cracks were observed close to the TBs on prestrained specimens while no secondary cracks were noticed for asreceived specimens (Figs. 16 and 17). The macroscopic stress level applied during the pre-straining up to $1250 \mathrm{MPa}$ was sufficient to develop plasticity in selected grains in the form of slip bands, especially close to favorably oriented TB (Fig. 10a). For similar reasons than those discussed in Section 4.1.1, the twin responsible for crack initiation has a relatively high Schmid factor parallel to the twin boundary in both the grains $(\mu>0.44)$ and the twin and the parent grain shows a high difference in elastic moduli on either side of the TB. Those microstructural parameters favoring crack initiation at twin boundaries are in good agreement with those recently defined by Stinville et al. [15].

\section{Conclusions}

The low stress/very high cycle fatigue behavior of three different DA718 microstructures was studied at room temperature at a strain amplitude of $0.22 \%$ on as received and pre-damaged specimens. Some conclusions from the present work are detailed below.

1. The microstructure having the largest grain size and the lowest twin boundary density demonstrated a significantly higher cyclic life compared to finer grain microstructures.

2. All fatigue cracks initiated from surface or near-surface NMIs or near large favorably oriented twins due to the high anisotropic elastic properties of nickel-based superalloys and the strong differences in elastic properties between NMIs and the surrounding metallic matrix.

Table 3

Elastic properties of the superalloy, the titanium nitride and the niobium carbide at room temperature.

\begin{tabular}{|c|c|c|c|c|c|c|c|}
\hline Material & $\mathrm{C}_{11}$ (GPa) & $\mathrm{C}_{12}(\mathrm{GPa})$ & $\mathrm{C}_{44}(\mathrm{GPa})$ & A (Zener) & $\mathrm{E}<001>$ (GPa) & $\mathrm{E}<111>(\mathrm{GPa})$ & Reference \\
\hline Superalloy & 268 & 179 & 128 & 2.9 & 124 & 318 & {$[31]$} \\
\hline TiN & 625 & 165 & 163 & 0.7 & 556 & 417 & {$[32]$} \\
\hline NbC & 627 & 135 & 164 & 0.7 & 579 & 416 & {$[33]$} \\
\hline
\end{tabular}



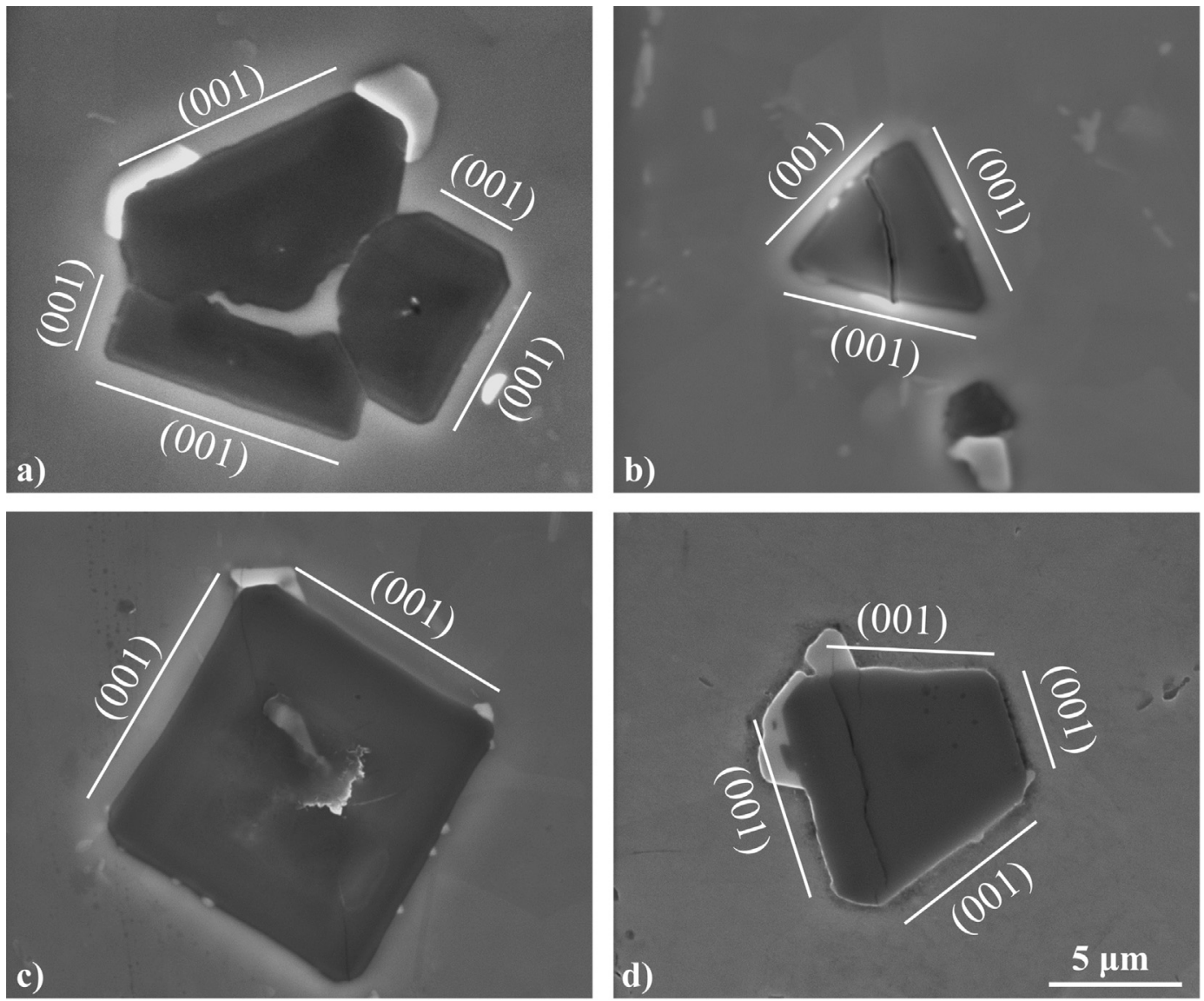

Fig. 19. TiN morphology in relation with crystallographic orientations.

3. For similar fine grain size microstructures, the transition of failure mode from $\Sigma 3 \mathrm{~TB}$ to NMIs correlated with the $\Sigma 3 \mathrm{~TB}$ density, with a higher $\Sigma 3$ TB density microstructure being less sensitive to NMI cracking. Despite failure mode differences, comparable lifetimes were found for these two DA718 microstructures.

4. Pre-cracked NMIs obtained by pre-straining the specimen in the plastic domain strongly affect the fatigue life of coarse grain microstructures due to plasticity and rough topography in the vicinity of the crack tip. However, this pre-damaging technique does not have a significant effect on fine grain microstructures.

5. Crack arrest from most of the pre-cracked NMIs into the surrounding metallic grains highlights the high small crack growth resistance of DA718 alloy under VHCF loading conditions.

6. While increasing the macroscopic yield strength of DA718 alloy, prestraining specimens in the early macroscopic plastic regime lead to a considerable fatigue life reduction due to cracks initiating within pre-cracked NMIs, from NMIs debonding or from high Schmid factor large twins.

7. While the stress/strain levels were relatively low for VHCF tests in comparison with high cycle fatigue (HCF) or low cycle fatigue (LCF) studies, similar microstructural initiation sites in DA718 were found. Brittle inclusions and favorably oriented large twins both favor crack initiation under cyclic loading at room temperature.

\section{Acknowledgments}

The authors are particularly grateful to Safran aircraft engines for providing the material and for financial support.

\section{References}

[1] D.D. Krueger, The development of direct age 718 for gas turbine engine disk applications, in: E.A. Loria (Ed.), Superalloy 718 Metall. Appl., Pittsburgh (USA), 1989: pp. 279-296.

[2] Y.C. Fayman, Microstructural characterization and elemental partitioning in a direct-aged superalloy (DA 718), Mater. Sci. Eng. 92 (1987) 159-171.

[3] D. Texier, A. Casanova Gomez, S. Pierret, J.-M. Franchet, T.M. Pollock, P. Villechaise, et al., Microstructural features controlling the variability in low cycle fatigue properties of alloy Inconel 718DA at intermediate temperature, Metall. Mater. Trans. A 47 (2016) 1096-1109.

[4] P.R. Bhowal, A.M. Wusatowska-sarnek, Carbides and their influence on notched low cycle fatigue behavior of fine-grained IN718 gas turbine disk material, in: E.A. Loria (Ed.), Superalloys 718, 625, 706 Deriv., Pittsburgh (USA), 2005: pp. 341349.

[5] B. Pieraggi, J.F. Uginet, Fatigue and creep properties in relation with alloy 718 microstructure, in: Superalloys 718, 625, 706 Deriv., Pittsburgh (USA), 1994: pp. $535-544$.

[6] T. Denda, P.L. Bretz, J.K. Tien, Inclusion size effect on the fatigue crack propagation mechanism and fracture mechanics of a superalloy, Metall. Trans. A 23 (1992) 519-526.

[7] L.A. James, The effect of grain size upon the fatigue-crack propagation behavior of alloy 718 under hold-time cycling at elevated temperature, Eng. Fract. Mech. 25 (1986) 305-314.

[8] N. Späth, V. Zerrouki, P. Poubanne, J.Y. Guedou, 718 superalloy forging simulation: a way to improve process and material, in: E.A. Loria (Ed.), Superalloys 718 625, 706 Var. Deriv., Pittsburgh (USA), 2001: pp. 173-183.

[9] F. Alexandre, S. Deyber, a Pineau, Modelling the optimum grain size on the low cycle fatigue life of a Ni based superalloy in the presence of two possible crack initiation sites, Scr. Mater. 50 (2004) 25-30.

[10] F. Alexandre, R. Piques, S. Deyber, A. Pineau, High temperature creep-fatigue crack initiation in 718-DA Ni based superalloy, in: Fract. Mech. beyond 2000 ECF14, Cracow (Poland), 2002.

[11] G.-J. Deng, S.-T. Tu, X.-C. Zhang, Q.-Q. Wang, C.-H. Qin, Grain size effect on the small fatigue crack initiation and growth mechanisms of nickel-based superalloy GH4169, Eng. Fract. Mech. 134 (2015) 433-450.

[12] F. Alexandre, Aspects probabilistes et microstructuraux de l'amorçage des fissures de fatigue dans l'alliage INCO 718, Ecole des Mines de Paris, 2004.

[13] S. Deyber, F. Alexandre, J. Vaissaud, A. Pineau, Probalistic life of DA718for aircraft engine disks, in: E.A. Loria (Ed.), Superalloy 718, 625, 706 Var. Deriv., Pittsburgh (USA), 2005: pp. 97-110.

[14] M. Abikchi, T. Billot, J. Crepin, A. Longuet, T.F. Morgeneyer, A. Pineau, Fatigue life and initiation mechanisms in wrought Inconel 718 DA for different microstructures, in: 13th Int. Conf. Fract., Beijing (China), 2013: pp. 1969-1979.

[15] J.C. Stinville, W.C. Lenthe, J. Miao, T.M. Pollock, A combined grain scale elastic- 
plastic criterion for identification of fatigue crack initiation sites in a twin containing polycrystalline nickel-base superalloy, Acta Mater 103 (2016) 461-473.

[16] C. Bathias, There is no infinite fatigue life in metallic materials, Fatigue Fract. Eng. Mater. Struct. 22 (1999) 559-565.

[17] Y. Murakami, T. Nomoto, T. Ueda, On the mechanism of fatigue failure in the superlong life regime ( $\mathrm{N}>107$ cycles). Part II: a fractographic investigation, Fatigue Fract. Eng. Mater. Struct. 23 (2000) 903-910.

[18] J. Miao, T.M. Pollock, J. Wayne Jones, Crystallographic fatigue crack initiation in nickel-based superalloy René 88DT at elevated temperature, Acta Mater. 57 (2009) 5964-5974.

[19] J. Miao, T.M. Pollock, J. Wayne Jones, Microstructural extremes and the transition from fatigue crack initiation to small crack growth in a polycrystalline nickel-base superalloy, Acta Mater. 60 (2012) 2840-2854.

[20] Q. Chen, N. Kawagoishi, Q.Y. Wang, N. Yan, T. Ono, G. Hashiguchi, Small crack behavior and fracture of nickel-based superalloy under ultrasonic fatigue, Int. J. Fatigue. 27 (2005) 1227-1232.

[21] J. Belan, The Fractography Analysis of IN 718 Alloy after Fatigue Test, Key Eng. Mater. 635 (2015) 9-12.

[22] J. Belan, High frequency fatigue test of In 718 alloy - microstructure and fractography evaluation, Metalurgija 54 (2015) 59-62.

[23] Y. Ono, T. Yuri, H. Sumiyoshi, E. Takeuchi, S. Matsuoka, T. Ogata, High-cycle fatigue properties at cryogenic temperatures in Inconel 718 nickel-based superalloy, Mater. Trans. 45 (2004) 342-345.

[24] Y. Zhang, Z. Duan, H.-J. Shi, Comparison of the very high cycle fatigue behaviors of INCONEL 718 with different loading frequencies, Sci. China Physics, Mech. Astron 56 (2013) 617-623.

[25] X.-F. Ma, Z. Duan, H.-J. Shi, R. Murai, E. Yanagisawa, Fatigue and fracture behavior of nickel-based superalloy Inconel 718 up to the very high cycle regime, J. Zhejiang Univ. Sci. A 11 (2010) 727-737.

[26] J.-R. Vaunois, J. Cormier, P. Villechaise, A. Devaux, B. Flageolet, Influence of both $y^{\prime}$ distribution and grain size on the tensile properties of UDIMET 720Li at room temperature., in: E.A. Ott, J.R. Groh, A. Banik, I. Dempster, T.P. Gabb, R. Helmink, et al. (Eds.), Superalloy 718 Deriv., Pittsburgh (USA), 2010: pp. 199-213.

[27] A. Shyam, C.J. Torbet, S.K. Jha, J.M. Larsen, M.J. Caton, C.J. Szczepanski, et al., Development of ultrasonic fatigue for rapid, high temperature fatigue studies in turbine engine materials, in: K.A. Green, T.M. Pollock, H. Harada, T.E. Howson, R.C. Reed, J.J. Schirra, et al. (Eds.), Superalloys 2004, Champion (USA), 2004: pp. 259-268.

[28] P. Peralta, L. Llanes, J. Bassani, C. Laird, Deformation from twin-boundary stresses and the role of texture: Application to fatigue, Philos. Mag. A 70 (1994) 219-232.

[29] A.C. Lewis, K.A. Jordan, A.B. Geltmacher, Determination of critical microstructural features in an austenitic stainless steel using image-based finite element modeling, Metall. Mater. Trans. A 39 (2008) 1109-1117.

[30] C. Blochwitz, W. Tirschler, Twin boundaries as crack nucleation sites, Cryst. Res. Technol. 40 (2005) 32-41.

[31] W. Hermann, H.G. Sockel, J. Han, A. Bertram, Elastic properties and determination of elastic constants of nickel-base superalloys by a free-free beam technique, in: R.D. Kissinger, D.J. Deye, D.L. Anton, A.D. Cetel, M.V. Nathal, T.M. Pollock, et al. (Eds.), Superalloys 1996, Champion (USA), 1996: pp. 229-238.

[32] J.O. Kim, J.D. Achenbach, P.B. Mirkarimi, M. Shinn, S. a Barnett, Elastic constants of single-crystal by line-focus acoustic microscopy nitride films measured, J. Appl. Phys. 72 (1992) 1805-1811.

[33] N. Rathod, S.D. Gupta, S.K. Gupta, P.K. Jha, First-principles study of structural, electronic, elastic, phonon, and thermodynamical properties of the niobium carbide, Solid State Phenom. 171 (2011) 67-77.

[34] B. Larrouy, P. Villechaise, J. Cormier, O. Berteaux, Grain boundary-slip bands interactions: Impact on the fatigue crack initiation in a polycrystalline forged $\mathrm{Ni}$ based superalloy, Acta Mater. 99 (2015) 325-336.

[35] A. Heinz, P. Neumann, Crack initiation during high cycle fatigue of an austenitic steel, Acta Metall. Mater. 38 (1990) 1933-1940.

[36] M.M. Shenoy, R.S. Kumar, D.L. McDowell, Modeling effects of nonmetallic inclusions on LCF in DS nickel-base superalloys, Int. J. Fatigue. 27 (2005) $113-127$.

[37] R. Prasannavenkatesan, C.P. Przybyla, N. Salajegheh, D.L. McDowell, Simulated extreme value fatigue sensitivity to inclusions and pores in martensitic gear steels, Eng. Fract. Mech. 78 (2011) 1140-1155.

[38] R. Prasannavenkatesan, J. Zhang, D.L. McDowell, G.B. Olson, H.-J. Jou, 3D modeling of subsurface fatigue crack nucleation potency of primary inclusions in heat treated and shot peened martensitic gear steels, Int. J. Fatigue. 31 (2009) 1176-1189.

[39] J. Zhang, R. Prasannavenkatesan, M.M. Shenoy, D.L. McDowell, Modeling fatigue crack nucleation at primary inclusions in carburized and shot-peened martensitic steel, Eng. Fract. Mech. 76 (2009) 315-334.

[40] P. Peralta, R. Dickerson, N. Dellan, K. Komandur, M.A. Jameel, Effects of local grain orientation on fatigue crack growth in multicrystalline fcc metallic materials, J. Eng. Mater. Technol. 127 (2005) 23-32.

[41] J.C. Stinville, M.P. Echlin, D. Texier, F. Bridier, P. Bocher, T.M. Pollock, Sub-grain scale digital image correlation by electron microscopy for polycrystalline materials during elastic and plastic deformation, Exp. Mech. 56 (2016) 197-216.

[42] D.D. Krueger, S.D. Antolovich, R.H. Van Stone, Effects of grain size and precipitate size on the fatigue crack growth behavior of Alloy 718 at $427^{\circ} \mathrm{C}$, Metall. Trans. A 18 (1987) 1431-1449.

[43] H. Mughrabi, Microstructural mechanisms of cyclic deformation, fatigue crack initiation and early crack growth, Philos. Trans. A Math. Phys. Eng. Sci. 373 (2015) 20140132.

[44] M. Zimmermann, Diversity of damage evolution during cyclic loading at very high numbers of cycles, Int. Mater. Rev. 57 (2012) 73-91.

[45] K.S. Chan, Roles of microstructure in fatigue crack initiation, Int. J. Fatigue. 32 (2010) 1428-1447.

[46] C.H. Lund, H.J. Wagner, Identification of Microconstituents in Superalloys, Colombus, OH, 1962.

[47] R. Soundararajan, Behavior of TiN inclusions and their influence in random grain formation in Ni-based superalloys, The University of British Columbia, 1998.

[48] A. Mitchell, S.L. Cockcroft, C.E. Schvezov, A.J. Schmalz, J.N. Loquet, J. Fernihough, Primary carbide and nitride precipitation in superalloys containing niobium, High Temp. Mater. Process 15 (1996) 27-40.

[49] A. Mitchell, The precipitation of primary carbides in IN718 and its relation to solidification, in: E.A. Loria (Ed.), Superalloys 718, 625, 706 Deriv., Pittsburgh (USA), 2005, pp. 299-310.

[50] S. Kalluri, G.R. Halford, M.A. McGaw, Prestraining and its influence on subsequent fatigue fife, in: M.R. Mitchell, R.W. Landgraf (Eds.), Adv. Fatigue Lifetime Predict. Tech. 3rd Vol, ASTM STP 1292, American S, 1996, pp. 328-341.

[51] C. Stöcker, M. Zimmermann, H.-J. Christ, Influence of prestraining on the higherature fatigue behaviour of polycrystalline nickel-based superalloys in the VHCF range, Procedia Eng. 2 (2010) 1383-1392.

[52] C. Stöcker, M. Zimmermann, H.-J. Christ, Effect of precipitation condition, prestrain and temperature on the fatigue behaviour of wrought nickel-based superalloys in the VHCF range, Acta Mater. 59 (2011) 5288-5304. 